\title{
Monarquía absoluta y desamortización municipal: los traspasos a censo perpetuo de Fernando VII*
}

\author{
Antonio Miguel Linares Luján ${ }^{1}$ \\ Universidad de Extremadura \\ alinares@unex.es
}

RESUMEN: La presente investigación pretende acabar con la idea de que la vuelta al trono de Fernando VII a partir de 1814 supuso la parálisis total de la política de desamortización municipal desarrollada en España por las Cortes de Cádiz. Las fuentes utilizadas para cumplir con esta pretensión proceden de las indagaciones que llevó a cabo la Dirección General de Propios y Arbitrios del Reino entre 1824 y 1833 para legitimar las ventas espontáneas producidas durante la Guerra de la Independencia. Estas averiguaciones, contrastadas con la escasa bibliografía existente para la monarquía fernandina, permiten detectar la presencia de una institución abiertamente partidaria de la privatización integral de la riqueza concejil y comunal en las entrañas mismas de la administración absolutista, así como la realización de decenas de transferencias en enfiteusis, autorizadas por la Corona y repartidas por toda la nación. La conclusión más relevante al respecto es que el doble reinado del último monarca absoluto (1814-1820 y 1823-1833) no solo no dejó en suspenso el proceso enajenador, reavivado al calor del conflicto napoleónico, sino que, hasta cierto punto, contribuyó a legitimarlo e, incluso, a diversificarlo con nuevos modelos de traspaso.

Palabras ClaVe: Fernando VII; absolutismo; desamortización municipal; patrimonio concejil y comunal; censo enfitéutico.

* Archivos citados: Archivo Histórico Nacional, Madrid (AHN), Biblioteca Digital de Castilla y León (BDCL).

${ }^{1}$ ORCID iD: https://orcid.org/0000-0002-9505-6669.

Copyright: (C) 2020 CSIC. Este es un artículo de acceso abierto distribuido bajo los términos de una licencia de uso y distribución Creative Commons Reconocimiento 4.0 Internacional (CC-BY 4.0) 


\section{Absolute monarchy and municipal disentailment: the sales to perpetual census of Ferdinand VII}

ABSTRACT: The present investigation seeks to put an end to the idea that the return to the throne of Ferdinand VII after 1814 totally paralysed the municipal disentailment policy implemented in Spain by the Cortes de Cádiz. The sources used in the research are the result of inquiries made by the Dirección General de Propios y Arbitrios del Reino between 1824 and 1833 to legitimize sales that took place during the Spanish War of Independence. These investigations, contrasted with the scant bibliography for Ferdinand VII's monarchy, reveal an institution which openly defended the wholesale privatization of the council and communal wealth at the heart of the absolutist administration, as well as the execution of dozens of emphyteusis transfers, authorized by the Crown and distributed throughout the nation. The most relevant conclusion in this regard is that, during the double reign of the last absolute monarch (1814-1820 and 1823-1833), the privatization process rekindled under cover of the Napoleonic conflict was not only not suspended but, to some extent, was legitimized and even diversified with the introduction of new transfer models.

KEY WORDS: Ferdinand VII; absolutism; municipal disentailment; council and communal patrimony; emphyteutic census.

CÓMO CITAR ESTE ARTÍCULO/CITATION: Linares Luján, Antonio Miguel, «Monarquía absoluta y desamortización municipal: los traspasos a censo perpetuo de Fernando VII», Hispania, 80/264 (Madrid, 2020): 109-137. https://doi.org/10.3989/hispania.2020.004.

\section{INTRODUCCIÓN}

Desde los años sesenta del pasado siglo, el interés por los distintos procesos de privatización que ha sufrido el patrimonio municipal (concejil y comunal) ${ }^{2}$ ha estado siempre presente en la historiografía española. Cierto es que, tras el «boom» de los setenta y los ochenta, vinculado a los estudios específicos sobre la aplicación de la Ley de Desamortización General de 1 de mayo de 1855 o Ley de Pascual Madoz, dicho interés empezó a remitir³. En ningún

2 Dentro del patrimonio «concejil» cabría distinguir entre bienes de propios y arbitrios y, dentro del «comunal», entre comunes, baldíos y realengos. En la terminología del Antiguo Régimen, los propios eran los predios que servían para cubrir los gastos ordinarios de cada concejo, mientras que los arbitrios eran aquellos otros que, siendo de común aprovechamiento, eran temporalmente arrendados para financiar los gastos extraordinarios. Los espacios comunes o de común y baldio eran terrenos de uso libre y gratuito («de balde») para los vecinos de un determinado pueblo o de pueblos colindantes. El mismo destino tenían los baldíos y realengos, pero en ellos la Corona ostentaba el dominio eminente. Véase NIETO, 1964.

${ }^{3}$ RUEDA, 9 (Madrid, 1986): 191-220. SÁEZ POMBO y MANUEL, 55 (Madrid, 1990): 315-383. GARCÍA PÉREZ, 9 (Madrid, 1993): 105-173. 
momento, sin embargo, el tema ha sido totalmente abandonado ${ }^{4}$ Y no solo por la relevancia que adquirieron las ventas en pública subasta practicadas a la luz de la citada ley, sino por la constatación de que estas ventas no fueron más que la culminación de una larga construcción social que, desarrollada a través de formas de apropiación distintas a la consagrada en 1855, fue capitalizada por la monarquía absoluta y, más tarde, encajada en la política económica liberal ${ }^{5}$.

La propia revisión historiográfica a la que ha sido sometida la desamortización municipal en España ha revelado que ni siquiera la decretada por Pascual Madoz pudo ser ajena a esas otras vías de privatización ${ }^{6}$. La prueba más evidente es la redención de censos a la que dio lugar la mismísima Ley de 1 de mayo de 1855, en la que confluyeron, indistintamente, los repartos iniciados durante el reinado de Carlos III, los rompimientos arbitrarios desatados tras la invasión napoleónica y los repartos a censo de los primeros decenios del siglo $\mathrm{XIX}^{7}$. Esta confluencia de procesos no agota, además, la diversidad de fórmulas que adoptó la apropiación individual de la riqueza concejil y comunal antes de la consolidación del liberalismo. De ella quedan fuera, por ejemplo, las ventas de la Guerra de la Independencia ${ }^{8}$, pero también, por supuesto, los muchos traspasos producidos durante el Antiguo Régimen bajo el amparo de la Corona.

Hasta ahora, sin embargo, pocos, muy pocos, han sido los trabajos que, reconociendo este hecho, han tratado de seguir el rastro del proceso privatizador durante la última monarquía absoluta (1814-1820 y 1823-1833). Salvo alguna que otra referencia de pasada al Real Decreto de 5 de agosto de $1818^{9}$, sobre el que más tarde volveremos, las monografías dedicadas a la privatización decimonónica, eclesiástica y civil, han saltado de la Guerra de la Independencia al Trienio Liberal y, de ahí, a la Regencia de María Cristina sin hacer siquiera una breve pausa para contemplar la intensa actividad legislativa del doble reinado de Fernando VII en materia de desamortización municipal.

${ }^{4}$ LÓPEZ ESTUDILLO, 65 (Madrid, 1992): 65-99. GONZÁLEZ MARZO, 1993; 2008. IRIARTE-GOÑI, 1996. JIMÉNEZ BLANCO, 1996. LANA y DE LA TORRE, 2001. LINARES, 2002. LANA, 1 (San Sebastián, 2004): 437-452. FERNÁNDEZ PARADAS, 2002; 34 (Murcia, 2004a): 39-60; 7/21 (Logroño, 2010): 1-27. GARCÍA RODRÍGUEZ, 2015. DEL VALLE, 2015; 69 (Murcia, 2016): 105-135.

${ }^{5}$ LINARES, 2016: 260.

${ }^{6}$ CASTRILLEJO, 1987. ARTIAGA, 1991. DÍEZ ESPINOSA, 9 (Madrid, 1993): 61-104. GARCÍA GONZÁLEZ, 1996. JIMÉNEZ BLANCO, 1996. GONZÁLEZ MARZO, 2008. GARCÍA RODRÍGUEZ, 2015.

7 JIMÉNEZ BLANCO y LINARES, 74 (Murcia, 2018): 37-66.

${ }^{8}$ FERNÁNDEZ DE PINEDO, 1974. ZULUETA, 36/140-141 (Madrid, 1975): 1.157-1.185. ALONSO, 1986. SÁNCHEZ SALAZAR, 55 (Madrid, 1990): 125-166. OTAEGUI, 1991. DE LA TORRE, 1991. FUENTES, 1993. LINARES, 9 (Murcia, 1995): 87-127.

9 NIETO, 1964: 862-863. TOMÁS Y VALIENTE, 1971: 65-66. FONTANA, 1985: $224-$ 225. RUEDA, 1997: 29-33. GÓMEZ URDÁÑEZ, 27 (Murcia, 2002): 139. 
Tal y como han advertido recientemente algunos estudiosos, la omisión ha llegado a ser tan generalizada dentro de la historiografía española que resulta difícil no incurrir tácitamente en una falsa contraposición: absolutismo-amortización frente a liberalismo-desamortización ${ }^{10}$. De esta manera, haciendo abstracción de las transferencias promovidas y protagonizadas en el pasado por la Corona, la última monarquía absoluta ha quedado injustificadamente definida como una etapa de parálisis total en la larga y compleja disolución de la riqueza concejil y comunal ${ }^{11}$.

Las páginas que siguen pretenden corregir en la medida de lo posible esa errónea visión de la realidad, rememorando los proyectos de desamortización municipal que vieron la luz en tiempos de Fernando VII y, sobre todo, poniendo cifras, por primera vez en la historiografía española, a todos los traspasos realizados en el conjunto del país durante la Década Ominosa. Con esta doble finalidad, además de la presente introducción, el texto ha sido estructurado en cuatro partes. La primera de ellas sintetiza las claves de la privatización concejil y comunal durante el Antiguo Régimen, haciendo especial hincapié en el papel de primer orden que jugó al respecto la monarquía absoluta. La segunda parte repasa la actividad legislativa de la primera restauración fernandina y revisa tanto las propuestas de desamortización que emanaron de las entrañas mismas de la Corona durante la segunda reacción absolutista, como la legislación en la que finalmente acabaron diluidas. La tercera presenta, en exclusiva, las cifras que arrojó la privatización municipal de la Década Ominosa según la información recopilada en su día por la Dirección General de Propios y Arbitrios del Reino. La cuarta y última resume las principales conclusiones que se derivan de la presente investigación.

\section{La DESAMOrtización MUNiCipal EN EL ANTIGUo RÉgimen}

Pese a la inalienabilidad con la que la monarquía absoluta revistió a la propiedad amortizada en manos de la administración local desde la Reconquista ${ }^{12}$, una de las citas obligadas en la larga historia de la privatización concejil y comunal es la que conforman las ventas de baldíos que patrocinó la propia Corona durante el siglo XVI ${ }^{13}$. No fueron estas, sin embargo, las primeras ni

\footnotetext{
${ }^{10}$ LINARES, 2016: 277.

11 «Cuando observamos los acontecimientos de estos años - dice J. Fontana al hablar del último reinado de Fernando VII - el inmovilismo desaparece, para dar paso a lo que parecen ser violentas fluctuaciones, bandazos irracionales», FONTANA, 1983: 42.

12 NIETO, 1964: 476-495.

13 GÓMEZ MENDOZA, 28/109 (Madrid, 1967). VASSBERG, 37/142 (Madrid, 1976); 1983. GARCÍA SANZ, 144 (Madrid, 1980): 95-127. LOPEZ-SALAZAR y GUTIÉRREZ
} 
las únicas ${ }^{14}$. Es más, tal y como ha puesto de relieve A. Marcos Martín para Castilla la Vieja, muchas de ellas respondieron a la previa usurpación de tierras por parte de la aristocracia señorial o por parte de la propia vecindad, unas veces sin autorización alguna $\mathrm{y}$, otras, con la aquiescencia de la autoridad local ${ }^{15}$. Esta parece haber sido la tónica predominante en la mayor parte del país durante toda la Edad Moderna, aunque con un matiz añadido: el papel disolvente que, a través del incremento de la presión fiscal, jugó el absolutismo ${ }^{16}$. No en vano muchos concejos, con el fin de responder a los crecientes requerimientos del Tesoro Real, además de enajenar el uso de antiguos predios de aprovechamiento común, el método más extendido, tendieron también a privatizar parte de la propiedad municipal, gravándola con censos «al quitar» $\rangle^{17} \mathrm{o}$, simplemente, vendiéndola al mejor postor.

Otras veces no fue la voracidad fiscal sino la indiferencia con la que la monarquía absoluta atendió a las urgencias más básicas de la vida local la que presionó en favor de la enajenación. La asistencia sanitaria, la educación primaria o la construcción y reparación de obras públicas exigieron desembolsos que tuvieron que ser cubiertos a través de la privatización ${ }^{18}$. Por activa o por pasiva, la actuación de la Corona en la vida local contribuyó a crear una atmósfera propicia para la desamortización municipal. De ella, obviamente, fueron las oligarquías agrarias las que, en connivencia con la autoridad consistorial, resultaron más favorecidas. Pero tampoco fueron las únicas beneficiarias. $\mathrm{Al}$ fin y al cabo, la arbitrariedad de la elite rural para con la riqueza municipal pudo justificar muchas veces la quiebra de la solidaridad vecinal — la llamada «economía moral» de la comunidad-y la eclosión de la codicia o de la simple lucha por la supervivencia dentro de la misma colectividad.

Con razón o sin razón, el comportamiento furtivo de los propios vecinos estuvo siempre presente en el proceso privatizador ${ }^{19}$. No todos, por supuesto, disfrutaron del mismo grado de encubrimiento para perpetrar el delito o para mantener el despojo. Quien más tuvo, más pudo y, seguramente, más retuvo. El volumen de lo sustraído debió de estar proporcionalmente relacionado con los medios técnicos del usurpador y con los límites físicos del patrimonio que permitió disimular el delito. Aun así, la alteración ilegal de los linderos originarios

NIETO, 1986. BRAVO y FERNÁNDEZ PARADAS, 28 (Granada, 2001): 83-103. MARCOS MARTÍN, 2008.

${ }^{14}$ Sobre la venta de baldíos en el siglo XVII y XVIII: DOMÍNGUEZ ORTIZ, 1984. FERNÁNDEZ CARRIÓN, 2/3 (Madrid, 1984): 163-182. RODRÍGUEZ SILVA, 1986. CALVO, 55 (Madrid, 1990): 95-123. CORONAS, 1994. CABRAL, 1995. FERNÁNDEZ PARADAS, 2004b.

${ }^{15}$ MARCOS MARTÍN, 1997: 61-63.

${ }^{16}$ LINARES, 2002: 118-119.

17 Véase GÓMEZ ÁLVAREZ, 6 (Valencia, 1977): 16.

18 GARCÍA SANZ, 144 (Madrid, 1980): 95-127. JIMÉNEZ BLANCO, 1996. LINARES, 2002. FERNÁNDEZ PARADAS, $2004 \mathrm{~b}$.

19 MAGAS NAVAS, 1981: 238-242.

Hispania, 2020, vol. LXXX, n. ${ }^{\circ} 264$, enero-abril, págs. 109-137, ISSN: 0018-2141, e-ISSN: 1988-8368 https://doi.org/10.3989/hispania.2020.004 
en predios de carácter concejil o comunal fue probablemente la única vía de acceso a la propiedad con la que contó un amplio sector, el menos favorecido, de la población rural.

Para otros grupos, generalmente ajenos a la comunidad, la apropiación individual resultó mucho más fácil. En esta tesitura estuvieron, por ejemplo, las «mercedes» con las que la monarquía borbónica, a pesar de las quejas que suscitó el intento de Felipe V de vender de nuevo los baldíos en $1737^{20}$, recompensó caprichosamente los servicios prestados a la Corona por destacadas figuras de la vida política o militar. Según confirma la experiencia extremeña, las tierras transferidas a través de esta vía, mayoritariamente baldías o realengas, fueron concedidas en «calidad de adehesadas y acotadas perpetuamente para el otorgante y sus herederos, con facultad para hacer vínculo y mayorazgo de todas ellas»». En contrapartida, las familias beneficiarias, además de edificar casas de habitación, quedaron obligadas a desbrozar, roturar, cultivar y plantar de acebuches, encinas o alcornoques las fincas otorgadas ${ }^{21}$.

En la misma línea repobladora, aunque sin la discrecionalidad de la merced territorial, estuvieron encuadradas las transferencias ordenadas, en exclusiva para Extremadura, por Real Decreto de 28 de abril de 1793, uno de los pocos mandatos que convirtió el reparto reclamado por el reformismo agrario ilustrado en un procedimiento verdaderamente privatizador ${ }^{22}$. Nacido del largo pleito mantenido contra el Honrado Concejo de la Mesta, el decreto intentó estimular el cultivo de terrenos incultos en la región, enajenándolos a censo con exención de derechos, diezmos y canon por diez años. Contempló, además, la posibilidad de refundir en poder de un solo titular el dominio del «suelo» y del «vuelo» en terrenos con arbolado perteneciente a los ayuntamientos ${ }^{23}$.

Pese a que desconocemos el monto total de los repartos producidos en virtud de este mandato y aunque son muchos los estudios que certifican el rechazo que generó entre los vecinos ${ }^{24}$, los datos disponibles para el conjunto de Extremadura atestiguan el significativo alcance que adquirieron estos traspasos ${ }^{25}$. En todo

${ }^{20}$ Las quejas planteadas al respecto por los representantes de los reinos de Castilla, León y Aragón obligaron a Fernando VI a reintegrar los baldíos enajenados durante el reinado de Felipe $\mathrm{V}$ y a reconocer a los municipios «en la misma posesión, uso y aprovechamiento en que estaban en el referido año de 1737», NIETO, 1964: 164-165.

${ }^{21}$ LINARES, 2002: 348.

${ }^{22}$ LINARES, 2012; 2016. Medida parecida, aunque en forma de licencia y no de providencia, fue la facultad concedida a las villas cántabras para repartir las tierras baldías (SÁNCHEZ SALAZAR, 1986).

${ }^{23}$ Sobre la importancia de este tipo de aprovechamientos concurrentes, véase FERNÁNDEZ ARROYO, (Cáceres, 1993): 523-544.

24 ZULUETA, 1975. GARCÍA PÉREZ y SÁNCHEZ MARROYO, 5 (Cáceres, 1984): 213 233. SÁNCHEZ SALAZAR, 1988a. PEREIRA y MELÓN, 1989. PÉREZ MARÍN, 17 (Salamanca, 1997): 261-284.

25 LINARES, 2002: 303.

Hispania, 2020, vol. LXXX, n. ${ }^{\circ}$ 264, enero-abril, págs. 109-137, ISSN: 0018-2141, e-ISSN: 1988-8368 
caso, más que por los efectos que generó, el Real Decreto de 28 de abril de 1793 resulta fundamental por cuanto ejemplifica el tímido, pero siempre latente, compromiso del absolutismo con el proceso privatizador.

De hecho, la Real Cédula de 21 de febrero de 1798, nacida esta vez de una nueva escalada en la deuda pública española, asumió sin rodeos tal compromiso al ordenar la venta de todas las casas pertenecientes a los propios y arbitrios del reino $^{26}$. Es verdad que, a diferencia del resto de medidas que conformaron la denominada «desamortización de Carlos IV»o «desamortización de Godoy»², la citada disposición dejó fuera de la enajenación a la riqueza rústica, la parte más importante, con diferencia, de la propiedad concejil y comunal. Qué duda cabe, sin embargo, que el hecho de poner en venta bienes de propios y arbitrios, directamente vinculados a la hacienda local y no a la difusa amalgama de baldíos y realengos de la que hasta entonces hizo uso la Corona cada vez que necesitó recomponer las cuentas de la Hacienda Real, supuso un salto cualitativo, casi irreversible, en el discurso desamortizador del Antiguo Régimen.

En todo caso, el momento más crítico y decisivo de este discurso no fue protagonizado por el absolutismo, ni por el liberalismo, sino por los traspasos realizados por muchos ayuntamientos del país con el fin de financiar el conflicto napoleónico. Fueron los abusos a los que, ante el vacío de poder reinante, dieron lugar estos traspasos los que motivaron el debate parlamentario del que nació el Decreto de 4 de enero de 1813 sobre reducción a dominio particular de «todos los terrenos baldíos o realengos y de propios y arbitrios» ${ }^{28}$, el primer mandato desamortizador del régimen liberal y uno de los de más alto contenido social $^{29}$. Cierto es que el discurso enajenador del liberalismo español no fue únicamente fruto de tales traspasos, pero también resulta innegable que, dado el difícil contexto en el que el Estado liberal fue instaurado en España, el hecho de tener que legitimar un proceso desamortizador espontáneamente dirigido por los propios concejos como el que tuvo lugar durante la Guerra de la Independencia representó, sin duda, una magnífica oportunidad ${ }^{30}$.

\section{LA POLÍTICA DE PRIVATIZACIÓN DURANTE LA REACCIÓN ABSOLUTISTA}

Durante los meses inmediatos al golpe de Estado de mayo de 1814, la monarquía fernandina intentó desmantelar la obra de las Cortes de Cádiz, empezando por la recomposición de la estructura institucional del Antiguo Régimen. En

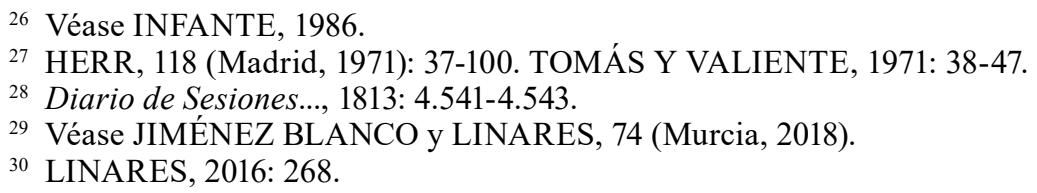


estas circunstancias, una de las primeras medidas adoptadas por la Corona con relación a la riqueza municipal fue la restitución de las competencias ejercidas tradicionalmente por el Consejo de Castilla y, desde 1760, por la Contaduría General de Propios y Arbitrios, en «la dirección, gobierno y administración de los propios del reino» ${ }^{31}$. En base a tan rápida restauración empezó a cuajar la ambigua respuesta de la última monarquía absoluta a las ventas espontáneas de la Guerra de la Independencia y, con ella, la imprecisa, por interesada, postura de Fernando VII respecto a la desamortización concejil y comunal.

La respuesta legal ha sido analizada en profundidad por A.M. Linares ${ }^{32}$ y, en consecuencia, no creemos necesario insistir en ella. Tan solo, si cabe, merece la pena retener algunas ideas. Por una parte, conviene precisar que, durante la primera reacción absolutista, la legalización de las ventas efectuadas tras la invasión de 1808 , muchas de ellas realizadas sin licencia ${ }^{33}$, aunque casi todas justificadas por la necesidad de financiar la contienda ${ }^{34}$, dejó escaso margen de maniobra para la validación de las transferencias. La legitimación, sin embargo, materializada en la Real Cédula de 21 de diciembre de $1818^{35}$, suscitó tantas dudas y dejó tantos cabos sueltos que, al final, una vez concluida la experiencia liberal del Trienio Constitucional, tendría que ser revisada nuevamente durante la segunda reacción absolutista. De la revisión saldría, como ahora veremos, una de las propuestas de privatización municipal más intrépidas de todas las discutidas en las altas esferas del Estado antes de la Ley de 1 de mayo de $1855^{36}$ : la del guipuzcoano Niceto Larreta, máximo responsable de la Dirección General de Propios y Arbitrios del Reino.

Por otra parte, la delicada situación de la hacienda española tras la independencia de las colonias americanas impediría renunciar, sin más, a la privatización $^{37}$. No por casualidad, entre las medidas adoptadas para reducir la carga de la deuda pública, el Real Decreto de 5 de agosto de 1818 contemplaba, además

${ }^{31}$ Real Cédula de 22 de agosto de 1814, AHN, Reales Cédulas, n. ${ }^{\circ} 2.248$.

${ }^{32}$ LINARES, 2012; 2016.

${ }_{33}$ Mención especial requiere la experiencia del País Vasco y Navarra: allí, fueron las Juntas Generales las que, a instancias de los municipios, autorizaron la enajenación desde 1808 (OTAEGUI, 1991: 40-53. DE LA TORRE, 1991: 97-100). También en Extremadura la iniciativa local fue prontamente reconducida a la legalidad por la Junta Suprema (Instrucción de 23 de noviembre de 1810). La rápida respuesta de la superioridad no pudo evitar, sin embargo, la arbitrariedad de las ventas realizadas en la región. Es más, las denuncias que presentó contra ellas el diputado extremeño Antonio Oliveros en enero de 1811 ante las Cortes Constituyentes fueron la raíz de la discusión parlamentaria que condujo al Decreto de 4 de enero de 1813 . Véase, al respecto, LINARES, 2012: 323-327.

${ }^{34}$ FONTANA, 69 (Madrid, 1981). FONTANA y GARRABOU, 1986.

${ }_{35}$ Decretos del Rey..., 1819, vol. V: 696-700.

${ }^{36}$ Para una visión detallada de los distintos proyectos de desamortización municipal planteados durante todo el siglo XIX, véase LINARES, 2012.

${ }^{37}$ FONTANA, 1971; 1987. COMÍN, 1990. 
del impuesto del 20 por 100 sobre los propios y arbitrios del reino en lugar del 10 por 100 estipulado hasta entonces, la venta de baldíos y realengos ${ }^{38}$, una medida a la que, como sabemos, había recurrido varias veces la Corona durante la Edad Moderna. La única novedad que introducía esta vez la monarquía estribaba en la procedencia inmediata de algunas de las fincas puestas a la venta. Y es que la Real Cédula de 22 de julio de 1819, aclaratoria del decreto anterior, disponía la subasta de los «baldíos y comunes enajenados durante la invasión francesa sin la autoridad necesaria $\rangle^{39}$. Es decir, sin despejar las dudas suscitadas por la Real Cédula de 21 de diciembre de 1818, la nueva disposición pretendía revender parte de las fincas privatizadas durante la Guerra de la Independencia. En estas circunstancias, la aplicabilidad de la medida resultaba bastante discutible. Política y legalmente hablando, sin embargo, la inclusión de los «comunes» entre los bienes susceptibles de reventa demostraba que, desde la Real Cédula de 21 de febrero de 1798 y una vez traspasada la delgada línea jurídica que separaba a baldíos y realengos de propios, arbitrios y comunes, el discurso privatizador del absolutismo había entrado en un punto de no retorno.

De hecho, ese mismo discurso acabaría dando, si no legitimidad, sí, al menos, protección a las otras formas de apropiación individual que había venido sufriendo la riqueza rústica municipal desde la Guerra de la Independencia. Hablamos de las roturas arbitrarias que habían proliferado en España a raíz de la invasión napoleónica ${ }^{40}$. Pese a la Restauración de 1814, dichas roturas no solo no serían desautorizadas, sino que, incluso, llegarían a ser promocionadas por la propia monarquía fernandina. Esa era, sin duda, la intención del Real Decreto de 31 de agosto de 1819 cuando eximía de diezmos y primicias a los roturadores de terrenos incultos que los redujeran «a un cultivo estable y permanente y no pasagero y temporal (sic) $\rangle^{41}$. Desde esta perspectiva, sería cuando menos pueril seguir pensando en la reacción absolutista como una mera vuelta atrás en la construcción política de la desamortización municipal. La ruptura de la legalidad vigente durante la Guerra de la Independencia había desatado las tendencias individualistas dentro de la comunidad rural y la monarquía de Fernando VII, tal y como había ocurrido previamente en Cádiz, no parecía estar dispuesta a negar la realidad. Sobre todo si, en base a ella, podía utilizar parte de la riqueza local para financiar la deuda de la Hacienda Real.

Con la mirada puesta en esta última posibilidad comenzaba a caminar también la segunda reacción absolutista en octubre de 1823. Tan solo cuatro meses

\footnotetext{
38 Decretos del Rey..., 1819, vol. V: 394-395.

39 Decretos del Rey..., 1823, vol. VI: 299-303.

40 JIMÉNEZ BLANCO, 1996: 99-100. JIMÉNEZ BLANCO y LINARES, 74 (Murcia,

${ }^{41}$ Decretos del Rey..., 1823, vol. VI: 340-345.
} 2018): 49-50. 
más tarde de la vuelta al trono de Fernando VII, la venta en pública subasta de baldíos y realengos pasaba nuevamente a formar parte de las medidas adoptadas por la Corona para financiar las obligaciones contraídas por la Real Caja de Amortización ${ }^{42}$. Tres días después, empezaba a circular la orden de devolución de todas las fincas de propios y arbitrios enajenadas durante la etapa anterior ${ }^{43}$. Quedaba así insinuada, desde las primeras medidas de la segunda restauración absolutista, la doble vara de medir con la que la monarquía fernandina asumía la privatización de la propiedad concejil y comunal: enajenación en pública subasta de baldíos y realengos e inalienabilidad de propios y arbitrios.

Para la administración de tales patrimonios, la Corona creaba esta vez una nueva institución: la Dirección General de Propios y Arbitrios del Reino. Constituida en abril de 1824 con dependencia exclusiva de la Secretaría de Hacienda, la recién estrenada entidad asumía parte de las funciones tradicionalmente ejercidas por el Consejo de Castilla ${ }^{44}$. Una de las primeras intervenciones de la nueva institución sería la consulta remitida por Niceto Larreta, titular de la Dirección General, a la Secretaría de Hacienda en septiembre de 1825. En ella, el brillante ejecutivo vasco resucitaba el tema de las ventas realizadas durante la Guerra de la Independencia, insistiendo en las dudas suscitadas a raíz de la publicación de la Real Cédula de 21 de diciembre de $1818^{45}$.

La consulta no obtendría respuesta hasta la Real Instrucción de 13 de octubre de 1828, en la que quedarían definitivamente perfiladas las atribuciones específicas de la nueva Dirección General de Propios y Arbitrios del Reino. Dentro de tales competencias, la instrucción prescribía la realización de una precisa investigación sobre las fincas que hubieran sido vendidas desde la invasión napoleónica, proponiendo la confirmación de las ventas realizadas durante la contienda, «siempre que resulte no hubo en ellas más defecto que la falta de licencia y que sus productos se convirtieron en objeto de Real Servicio», así como la anulación de las que carecieran de tales requisitos ${ }^{46}$.

En vista del encargo y de los reparos originados al respecto ${ }^{47}$, el 23 de febrero de 1830, Niceto Larreta presentaba ante la Secretaría de Hacienda una

42 «Real Decreto de 4 de febrero de 1824», Decretos del Rey..., 1824, vol. VIII: 106-111.

${ }^{43}$ Circular de 7 de febrero de 1824, AHN, Reales Cédulas, n. ${ }^{\circ} 3.348$.

${ }^{44}$ GARCÍA GARCÍA, 1994: 422.

${ }^{45}$ La citada memoria está inserta en la Exposición hecha por la Dirección General de Propios y Arbitrios del Reino al Ministerio de Hacienda en 23 de febrero de 1830 sobre enagenaciones de fincas de Propios en las épocas de la Guerra de la Independencia y gobierno constitucional (sic), AHN, Ministerio del Interior (Gobernación), 1830, leg. 2.699-1, s/n.

${ }^{46}$ Decretos del Rey..., 1829, vol. XIII: 320-349.

47 Entre ellos, según aclaraba el propio Niceto Larreta en febrero de 1830, habría que incluir los manifestados por la Contaduría General de Propios y Arbitrios del Reino: ¿quedaban derogadas por la Instrucción de 13 de octubre de 1828 las reglas establecidas en la Real 
propuesta de privatización que intentaba armonizar las distintas partes implicadas en las ventas de la Guerra a través de una solución más o menos salomónica. En esencia, la propuesta devolvía a los concejos el dominio directo de los patrimonios vendidos entre 1808 y 1814, dejando en manos de los adjudicatarios, a cambio de un canon perpetuo, el dominio útil de los predios enajenados durante el conflicto. No sería reintegrado, en ningún caso, el capital invertido en la compra, pero sí parte de las sumas empleadas en la mejora de las fincas transferidas a manos privadas.

Era esta la primera entrega de una de las propuestas de desamortización más completas y atrevidas de todas las planteadas antes de la Ley de 1 de mayo de 1855. Materializada en una nueva memoria, enviada a la Secretaría de Hacienda el 19 de agosto de 1831, la última iniciativa de Niceto Larreta preveía, básicamente, una única medida:

... la enagenación a censo enfitéutico perpetuo del dominio útil de todas las fincas rústicas y urbanas, «no solo de propios, apropiados o arbitrados, sino también de todos los demás que, bajo cualquier concepto o denominación que se quiera, corresponden a los pueblos, tales como los comunes de común aprovechamiento, concejiles, senaras, dehesas carniceras, baldíos y realengos, así como los llamados de mancomunidad de pastos», esceptuando únicamente, por ahora, de dicha enagenación sus dehesas boyares en aquellos pueblos que la tengan señalada en los reglamentos, así como los exidos, las plazas y las heras para trillar (sic).

Para los montes de los pueblos, el director general preveía una consideración especial, distinguiendo previamente entre cuatro clases distintas: los montes bajos «que no tienen arbolado bravo», los terrenos «que carecen en la actualidad de toda clase de arbolados y solo producen argomales, espinos y otras plantas», aquellos otros «con árboles a bastante distancia unos de otros» $\mathrm{y}$, por último, los montes «en los que los árboles se hallan muy unidos o apiñados». Los de primera y segunda clase debían ser enajenados sin reparo alguno porque solo servían de guarida para fieras y ladrones o «de pretesto a los bagamundos para ir a ellos a cortar algunos haces de leña (sic)». También los de tercera clase podían ser desamortizados, aunque con la condición expresa de conservar el arbolado. Solo los montes completamente poblados debían de ser exceptuados, aunque - matizaba Niceto Larreta - sería conveniente repartirlos en suertes entre los vecinos, «reservándose siempre los ayuntamientos el dominio directo (...) de los troncos de los árboles» ${ }^{48}$.

Cédula de 21 de diciembre de 1818 ? ¿Podían considerarse objetos del «Real Servicio» los suministros confiscados por las tropas enemigas?

48 Propuesta hecha al Ministerio de Hacienda en 19 de Agosto de 1831 para la enagenación a censo enfitéutico de todas las fincas de propios (sic), AHN, Ministerio del Interior (Gobernación), 1831, leg. 2.700, s/n. 
Más radical se mostraba al respecto José Rey Alda, subdelegado de propios y arbitrios de Extremadura, en el informe solicitado por la Secretaría de Hacienda para conocer la opinión de los intendentes. El subdelegado extremeño consideraba perverso exceptuar el monte alto en los terrenos de propios, arbitrios, baldíos y comunes. Separar el suelo y el vuelo sería, según él, reproducir los perjuicios que tradicionalmente ocasionaban los condominios. Con este matiz, Rey Alda juzgaba el plan de Niceto Larreta como el más útil de todos los ideados hasta entonces para incrementar el valor del patrimonio concejil y comunal, multiplicar el número de propietarios en todo el país y, algo realmente sorprendente si no fuera por la creciente amenaza carlista, ganar adeptos a los derechos del trono ${ }^{49}$.

Pese al apoyo de otros muchos intendentes de provincia, la Contaduría General de Propios y Arbitrios desestimaba el proyecto en febrero de $1833^{50}$. La desestimación no implicaba, sin embargo, una renuncia total a la privatización, sino, más bien, una apuesta por la enajenación gubernativa. Esta era, en definitiva, la fórmula que había acabado imponiendo la restauración absolutista. Consistía, básicamente, en la emisión de una real orden de aprobación para cada una de las transferencias que, bajo demanda y tras la aprobación de la autoridad competente, conviniera realizar. Cada enajenación sería desarrollada en el tiempo y en la forma que exigieran las circunstancias. Unas veces, la opción más adecuada sería la venta en pública subasta y, otras, la adjudicación a censo enfitéutico ${ }^{51}$. Hasta aquí, la legislación. Más tarde comprobaremos hasta dónde llegaría la realidad.

Por ahora, convendría hacer una breve, pero necesaria, reflexión sobre la política fernandina en materia de desamortización municipal. De partida, cabría afirmar que, aun cuando la enajenación gubernativa, léase «a la carta», recordaba más a la merced territorial del siglo XVIII que a la reforma agraria insinuada por las Cortes de Cádiz, la aparición en el seno del absolutismo de una institución abiertamente partidaria de la privatización no solo contribuía a mantener viva la idea de seguir profundizando en la desamortización concejil y comunal, sino que suponía realmente una escalada más en la desarticulación del Antiguo Régimen. No en vano la inclusión de baldíos y realengos entre los

49 Informe del Intendente Subdelegado de Propios de Extremadura sobre enagenación a censo enfitéutico perpetuo de todas las fincas de propios, apropiados y arvitrados, conservando el arbolado alto o bravo que tuvieren (sic), AHN, Ministerio del Interior (Gobernación), 1832, leg. 2.699-2, s/n.

50 Informe evacuado por la Contaduría General de Propios en 27 de Febrero de 1833 acerca del proyecto que en 19 de Agosto de 1831 presentó al Ministerio la Dirección de los mismos ramos para la enagenación a censo enfitéutico del dominio útil de todas las fincas rústicas y urbanas de dichos propios (sic), AHN, Ministerio del Interior (Gobernación), 1833, leg. $2.698, \mathrm{~s} / \mathrm{n}$.

${ }^{51}$ «Real Decreto de 31 de diciembre de 1829», Decretos del Rey..., 1830, vol. XIV: 355-356.

Hispania, 2020, vol. LXXX, n. ${ }^{\circ} 264$, enero-abril, págs. 109-137, ISSN: 0018-2141, e-ISSN: 1988-8368

https://doi.org/10.3989/hispania.2020.004 
predios que, según precisaba Niceto Larreta, «corresponden a los pueblos», dejaba malherida la supuesta titularidad real sobre la que había reposado tradicionalmente la enajenación, más o menos caprichosa, de estos patrimonios.

Por otra parte, la idea de privatizar para evitar que los «vagamundos» de los que hablaba el director general de propios y arbitrios, seguramente simples vecinos o comuneros, completaran los ingresos domésticos con los recursos procedentes del aprovechamiento comunal entroncaba directamente con la voluntad de liberalizar - abaratar - el mercado de trabajo en el mundo rural ${ }^{52}$, una pretensión insinuada por los diputados de Cádiz y desarrollada por el liberalismo más maduro del Bienio Progresista ${ }^{53}$. En la misma línea apuntaba la frontal oposición del intendente de Extremadura, José Rey Alda, a la permanencia de los condominios en los montes de los pueblos, oposición que conectaba claramente con la idea liberal de «perfeccionar» la propiedad ${ }^{54}$. ¿Y qué decir de la intención de utilizar la desamortización municipal como una forma de captar adeptos a la causa absolutista? La conexión con el Decreto de 4 de enero de 1813 era tan evidente que difícilmente podríamos seguir hablando de ruptura o parálisis al definir la política de privatización de la monarquía fernandina.

\section{LA DESAMORTIZaCión gUbERnATIVA de FERNANDo VII}

Salvo algún que otro dato disperso e inconexo, generalmente diluido entre los complejos pleitos a los que dieron lugar los traspasos autorizados por Fernando VII, pocos, por no decir ninguno, son los estudios que han interpretado cada uno de estos testimonios como el fragmento de un proceso privatizador mucho más amplio, con efectos en todo el territorio naciona $1^{55}$. Gracias, sin embargo, a los antecedentes que aporta la tesis doctoral de Carmen García García ${ }^{56}$ y gracias también a la casualidad, hace algunos años tuvimos la suerte de encontrar, entre los papeles que conserva el Archivo Histórico Nacional, una Relación circunstanciada en

52 Para José Rey Alda, la «inveterada costumbre» de coger manualmente la bellota de montanera en tierras de titularidad municipal sin pagar nada a cambio inutilizaba ricas encinas «para ponerlas en las manos de cuatro miserables» que, por obtener un poco de fruto sin sazonar, «pierden de trabajar y ganar un jornal muchos días, que es lo que a ellos y al Estado conviene», Informe del Intendente Subdelegado de Propios de Extremadura sobre enagenación a censo enfitéutico perpetuo de todas las fincas de propios, apropiados y arvitrados, conservando el arbolado alto o bravo que tuvieren (sic), AHN, Ministerio del Interior (Gobernación), 1832, leg. 2.699-2, s/n.

${ }_{53}$ LINARES, 2002: 591-599.

${ }^{54}$ Para una visión más matizada del debate historiográfico sobre el supuesto «perfeccionamiento» de la propiedad de la tierra a partir de la revolución liberal, véase CONGOST, 2000.

55 Tan solo LÓPEZ ESTUDILLO, 65 (Madrid, 1992): 68, parece haber captado el verdadero alcance de este proceso.

${ }^{56}$ GARCÍA GARCÍA, 1994. 
forma de estado ${ }^{57}$ sobre las fincas rústicas y urbanas enajenadas a censo perpetuo «desde la creación de la Dirección General de Propios y Arbitrios, en el año de 1824, hasta fin de Diciembre de 1832». Esta enumeración, elaborada conforme a lo prevenido por Niceto Larreta a principios de 1833, contiene referencias sobre la situación geográfica de tales fincas, «sus nombres, cabida, renta que producían, la que rinden en la actualidad, fecha de la real orden de su concesión, y los pueblos que han remitido copias de la escritura censual $»^{58}$.

En realidad, la información aportada por la Dirección General de Propios y Arbitrios del Reino no siempre resulta tan precisa. Para muchas de las fincas rústicas enajenadas, sobre todo las de pequeña extensión, la citada relación no detalla la superficie privatizada. La misma imprecisión contienen las noticias sobre la mayor parte de las fincas urbanas incluidas en la lista, fundamentalmente parcelas no edificadas, pero también molinos, pesos, bodegas, hornos o posadas. Tampoco la renta anterior a la fecha de enajenación aparece indicada en la inmensa mayoría de las propiedades recogidas por la fuente, posiblemente porque muchas de ellas nunca antes habían sido arrendadas. En algunas ocasiones, incluso, la estipulación en especie de la renta impuesta tras la cesión impide conocer y, por tanto, agregar la cuantía de una determinada transferencia. Otras veces, las menos, no queda reflejada la valoración en venta de los bienes enajenados. Por fortuna, sin embargo, en el 96,5 por 100 de los casos considerados (228 repartidos por todo el país) aparece recogido, en reales de vellón, el valor en venta y en renta de los predios adjudicados.

En conjunto, todos ellos suman un mínimo de cerca de 18.000 .000 reales en venta y de casi 385.000 reales de vellón en renta (cuadro 1). Hablamos, ciertamente, de una cifra exigua si la comparamos con los más de 4.000.000 reales estimados por la propia Dirección General de Propios y Arbitrios para la renta de las fincas vendidas durante la Guerra de la Independencia ${ }^{59}$, más aún cuando descubrimos que las dos terceras partes de la renta estipulada para todas las transferencias producidas entre 1824 y 1832 corresponden a una sola operación: la enajenación a censo de cerca de 253.000 hectáreas en los Montes de Toledo.

${ }^{57}$ Relación circunstanciada en forma de estado que manifiesta las fincas rústicas y urbanas que se han enagenado a censo perpetuo en todo el Reyno desde la creación de la Dirección General de Propios y Arbitrios, en el año de 1824, hasta fin de Diciembre de 1832, de sus nombres, cabida, renta que producian, la que rinden en la actualidad, fecha de la Real orden de su concesión, y los Pueblos que han remitido copias de la escritura censual, conforme a lo prevenido por el Ilustrísimo Señor Director General del ramo en $1^{\circ}$ de Enero presente (sic), AHN, Ministerio del Interior (Gobernación), 1833, leg. 2.699-1.

58 AHN, Ministerio del Interior (Gobernación), 1833, leg. 2.699-1.

59 Exposición hecha por la Dirección General de Propios y Arbitrios del Reino al Ministerio de Hacienda en 23 de febrero de 1830 sobre enagenaciones de fincas de Propios en las épocas de la Guerra de la Independencia y gobierno constitucional (sic), AHN, Ministerio del Interior (Gobernación), 1830, leg. 2.699 (1).

Hispania, 2020, vol. LXXX, n. ${ }^{\circ} 264$, enero-abril, págs. 109-137, ISSN: 0018-2141, e-ISSN: 1988-8368 
MONARQUÍA ABSOLUTA Y DESAMORTIZACIÓN MUNICIPAL: LOS TRASPASOS...

\begin{tabular}{|c|c|c|c|c|c|c|c|c|c|c|c|c|c|c|c|c|c|c|}
\hline \multirow{4}{*}{ 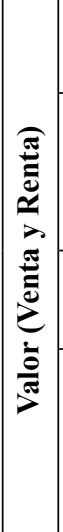 } & de $\frac{\bar{\pi}}{\theta}$ & & $\tilde{o}^{n}$ & $\tilde{o}^{n}$ & $\stackrel{0}{0}$ & & $\hat{\sigma}^{\circ}$ & $0_{0}^{\circ}$ & $\overbrace{0}^{n}$ & $\hat{m}_{0}^{2}$ & $\tilde{0}$ & $m_{m}$ & & & $\begin{array}{l}\infty \\
0 \\
0\end{array}$ & $\stackrel{?}{=}$ & $\underline{\sigma}$ & 0 \\
\hline & 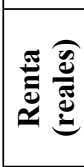 & & $\begin{array}{l}\stackrel{0}{0} \\
\stackrel{n}{-}\end{array}$ & $\begin{array}{l}0 \\
\infty \\
\infty \\
\infty\end{array}$ & $\begin{array}{l}0 \\
\cong\end{array}$ & & $\begin{array}{l}\nabla_{n} \\
\stackrel{2}{i}\end{array}$ & $\stackrel{\nabla}{\sigma}$ & $\hat{\tilde{y}}$ & $\begin{array}{c}0 \\
\stackrel{+}{ \pm} \\
\stackrel{\sim}{-}\end{array}$ & $\overrightarrow{8}$ & $\begin{array}{l}0 \\
0 \\
\infty \\
0 \\
1 \\
1\end{array}$ & & & 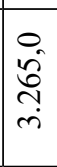 & $\begin{array}{l}0 \\
\infty \\
\infty \\
0 \\
i \\
i\end{array}$ & $\begin{array}{l}\stackrel{0}{0} \\
\stackrel{0}{+} \\
\stackrel{+}{r}\end{array}$ & $\begin{array}{l}0 \\
\infty \\
+\end{array}$ \\
\hline & oْ & & $\tilde{\sigma}$ & $\tilde{\sigma}$ & $\stackrel{\circ}{\circ}$ & & $\tilde{o}^{n}$ & $0_{0}$ & $\stackrel{\sigma}{0}^{\prime}$ & $\overrightarrow{0}$ & ֵֵ & $\cong$ & & & $\begin{array}{l}0 \\
0\end{array}$ & $\stackrel{0}{-}$ & $\stackrel{+}{\rightarrow}$ & $0_{0}$ \\
\hline & 跑 & & $\begin{array}{l}0 \\
\dot{8} \\
\stackrel{0}{0} \\
\ddot{\gamma}\end{array}$ & $\begin{array}{l}0 \\
2 \\
2 \\
n \\
0 \\
n\end{array}$ & $\begin{array}{l}0 \\
\stackrel{8}{8} \\
\stackrel{n}{+}\end{array}$ & & $\frac{\vec{m}}{\tilde{m}}$ & $\begin{array}{l}n \\
\frac{n}{n} \\
\dot{\sigma} \\
\dot{\gamma}\end{array}$ & $\begin{array}{l}\tilde{D} \\
\infty \\
\infty \\
\dot{\sigma}\end{array}$ & $\begin{array}{l}0 . \\
0 \\
8 \\
+ \\
\dot{f} \\
\dot{n}\end{array}$ & $\begin{array}{l}0 \\
\dot{8} \\
\dot{8} \\
\dot{0}\end{array}$ & 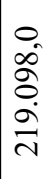 & & & $\begin{array}{l}m \\
\tilde{m} \\
\infty \\
\dot{g} \\
\tilde{\sigma}\end{array}$ & $\begin{array}{l}0 \\
\hat{b} \\
a \\
1 \\
\infty \\
-1\end{array}$ & $\begin{array}{l}\hat{\delta} \\
\stackrel{0}{0} \\
\infty \\
\dot{d} \\
\dot{d}\end{array}$ & $\stackrel{0}{a}$ \\
\hline 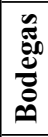 & $\ddot{z}$ & & & & & & & & & & & & & & & & & \\
\hline $\begin{array}{l}0 \\
0 \\
0 \\
0\end{array}$ & $\ddot{z}$ & & & & & & & & & & & & & & & & & \\
\hline 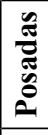 & $\ddot{z}$ & & & & & & & & & & & & & & & & & \\
\hline 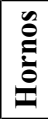 & $\ddot{Z}$ & & & & & & & & & & - & & & & & & & \\
\hline 氖 & $\ddot{Z}$ & & & & & & & & & - & & & & & & & & \\
\hline 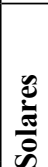 & $\Sigma$ & & & 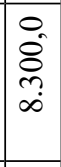 & & & & & & $\begin{array}{l}0 \\
6 \\
n \\
n \\
\\
\end{array}$ & & 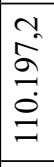 & & & & 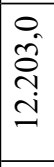 & & 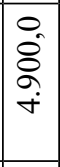 \\
\hline & $\ddot{z}$ & & & $m$ & & & $\sim$ & - & $m$ & $r$ & - & $\Xi$ & & & - & $\sim$ & & $\sim$ \\
\hline$\stackrel{\Xi}{\pi}$ & $\stackrel{\mathscr{E}}{\Xi}$ & & $\tilde{\sigma}^{N}$ & & $\begin{array}{l} \pm \\
\pm\end{array}$ & & 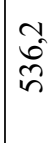 & & & & $\begin{array}{l}0 \\
\infty \\
\infty\end{array}$ & $\frac{a}{\vec{n}}$ & & & $\begin{array}{l}0 \\
\text { Dे } \\
\text { లn }\end{array}$ & 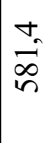 & $\stackrel{m}{\dot{q}}$ & \\
\hline & $\ddot{z}$ & & $\sim$ & & - & & $n$ & & & & $m$ & $r$ & & & & $m$ & & $\sim$ \\
\hline & & $\frac{\pi}{\frac{\pi}{\pi}}$ & 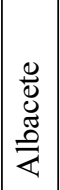 & 营 & 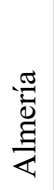 & $\frac{\pi}{3}$ & 莡 & $\frac{\mathscr{U}}{\mathscr{J}}$ & 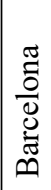 & $\begin{array}{l}0 \\
\stackrel{0}{0} \\
\stackrel{0}{\Xi} \\
0\end{array}$ & 总 & 赵 & 莣 & 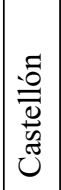 & 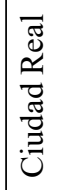 & 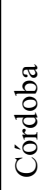 & 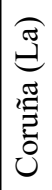 & త్ర \\
\hline
\end{tabular}

Hispania, 2020, vol. LXXX, n. ${ }^{\circ} 264$, enero-abril, págs. 109-137, ISSN: 0018-2141, e-ISSN: 1988-8368 https://doi.org/10.3989/hispania.2020.004 


\begin{tabular}{|c|c|c|c|c|c|c|c|c|c|c|c|c|c|c|c|c|c|c|c|}
\hline \multirow{4}{*}{ 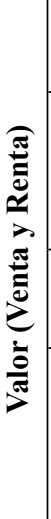 } & $\partial 0 \frac{\pi}{\theta}$ & $\stackrel{0}{\circ}$ & $\stackrel{0}{0}$ & $\tilde{o}^{m}$ & & $\tilde{n}$ & ్. & $\begin{array}{l}\infty \\
\text { i }\end{array}$ & & $\tilde{\sigma}^{n}$ & $\hat{m}^{n}$ & & $\tilde{n}_{0}^{n}$ & $\underset{r}{\sigma_{n}}$ & $\begin{array}{l}0 \\
0\end{array}$ & $\stackrel{0}{\circ}$ & & $\stackrel{0}{0}$ & $\stackrel{\infty}{0}^{\infty}$ \\
\hline & 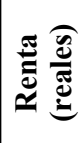 & مू & on & $\begin{array}{l}0 . \\
0 \\
0 \\
0\end{array}$ & & 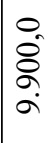 & $\begin{array}{l}0 \\
\stackrel{\infty}{\infty} \\
0\end{array}$ & $\begin{array}{l}n \\
\tilde{n} \\
\infty \\
0 \\
0\end{array}$ & & 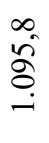 & $\begin{array}{l}\underset{+}{+} \\
\stackrel{\infty}{\sim}\end{array}$ & & $\begin{array}{l}\overrightarrow{0} \\
\stackrel{-}{-}\end{array}$ & $\begin{array}{l}n \\
\stackrel{n}{N} \\
\infty \\
\infty \\
\sim \\
\sim\end{array}$ & $\begin{array}{l}0 \\
\stackrel{8}{+}\end{array}$ & $\begin{array}{l}0 \\
\text { 음 }\end{array}$ & & $\begin{array}{l}0 \\
\infty\end{array}$ & 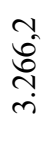 \\
\hline & $0^{\circ} \frac{\bar{\pi}}{\theta}$ & $\stackrel{\circ}{\circ}$ & $\stackrel{\circ}{0}$ & ra & & $\stackrel{\infty}{-}$ & ָூ & $\Leftrightarrow$ & & $\stackrel{\sim}{0}$ & $\hat{\sigma}_{0}^{n}$ & & $\tilde{o}$ & $\begin{array}{l}\nabla_{n} \\
\stackrel{n}{*}\end{array}$ & $\stackrel{0}{\circ}$ & $\stackrel{0}{0}$ & & $\overrightarrow{0}$ & $\stackrel{0}{-}$ \\
\hline & 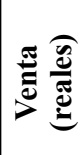 & 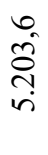 & $\stackrel{\circ}{\circ}$ & $\begin{array}{l}0 \\
\tilde{N} \\
\tilde{\sigma} \\
+ \\
\dot{\tilde{n}}\end{array}$ & & $\begin{array}{l}0 \\
8 \\
8 \\
\dot{8} \\
\stackrel{m}{m}\end{array}$ & $\begin{array}{l}\stackrel{0}{0} \\
\text { ஸे } \\
\stackrel{1}{0}\end{array}$ & 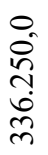 & & $\begin{array}{l}n \\
n \\
0 \\
n \\
0 \\
n\end{array}$ & $\begin{array}{l}\vec{\sigma} \\
\frac{\sigma}{6}\end{array}$ & & 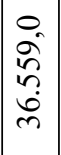 & 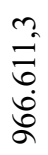 & $\begin{array}{l}0 \\
\stackrel{0}{0} \\
\stackrel{0}{0} \\
\dot{+}\end{array}$ & $\begin{array}{l}\stackrel{0}{8} \\
\stackrel{8}{0} \\
\text { i. }\end{array}$ & & $\begin{array}{l}\overrightarrow{0} \\
\hat{b} \\
0\end{array}$ & $\begin{array}{l}\infty \\
\stackrel{+}{ \pm} \\
\stackrel{+}{\Xi}\end{array}$ \\
\hline 巻 & $\ddot{z}$ & & & & & & & & & & & & & & & & & & \\
\hline $\begin{array}{l}\tilde{E} \\
\tilde{E} \\
\stackrel{0}{0}\end{array}$ & $\ddot{z}$ & & & & & & & & & & & & & & & & & & \\
\hline 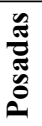 & $\ddot{z}$ & & & & & & & & & & - & & & & & & & & \\
\hline$\stackrel{\mathscr{O}}{\stackrel{0}{0}}$ & $\ddot{z}$ & & & & & & & & & & & & & & & & & & \\
\hline$\frac{\mathscr{O}}{\grave{g}}$ & $\ddot{z}$ & & & $N$ & & & - & & & - & & & & $N$ & & & & & \\
\hline \multirow{2}{*}{ 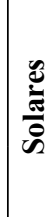 } & $\Sigma$ & & & $\begin{array}{l}\text { N } \\
\text { d } \\
\text { d }\end{array}$ & & & & $\begin{array}{l}\stackrel{0}{n} \\
\frac{n}{0} \\
\dot{\sigma}\end{array}$ & & & $\begin{array}{l}\stackrel{0}{g} \\
\text { bे } \\
\stackrel{1}{1}\end{array}$ & & & $\begin{array}{l}0 \\
\frac{0}{\sigma} \\
\sigma \\
\sigma\end{array}$ & & & & $\begin{array}{l}\vec{n} \\
\stackrel{n}{n}\end{array}$ & 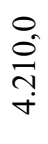 \\
\hline & $\ddot{z}$ & & & r & & & & $\nabla$ & & & - & & $N$ & $\simeq$ & & & & 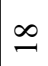 & $n$ \\
\hline \multirow{2}{*}{ 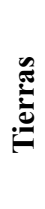 } & $\stackrel{\mathscr{E}}{\Xi}$ & $\stackrel{\dot{\sigma}_{0}}{\sigma_{0}}$ & $\stackrel{m}{=}$ & $\tilde{a}$ & & $\begin{array}{l}\text { ్. } \\
\text { ᄋ̊ } \\
\text { જุ }\end{array}$ & & $\begin{array}{l}0 \\
8 \\
8\end{array}$ & & $\stackrel{\infty}{0}$ & $\vec{n}$ & & $\begin{array}{l}\infty \\
\infty \\
\infty \\
\sigma \\
-\end{array}$ & $\begin{array}{l}\infty \\
\infty \\
0 \\
0\end{array}$ & $\frac{0}{i}$ & $\tilde{6}$ & & $\vec{\nabla}$ & $\begin{array}{l}r \\
\infty \\
\stackrel{n}{n} \\
\stackrel{\infty}{n}\end{array}$ \\
\hline & $\stackrel{\circ}{Z}$ & - & - & $\infty$ & & $N$ & & 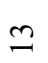 & & - & $\infty$ & & $\nabla$ & $\bar{m}$ & - & $m$ & & $\nabla$ & in \\
\hline & 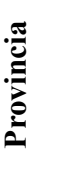 & 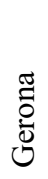 & 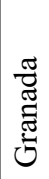 & $\begin{array}{l}\frac{\pi}{\pi} \\
\frac{\pi}{\pi} \\
\frac{\pi}{\pi} \\
\frac{\pi}{\pi} \\
0\end{array}$ & 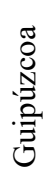 & $\frac{\stackrel{\pi}{D}}{\stackrel{D}{\Xi}}$ & 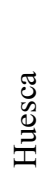 & 胥 & .ర్త్తే & 莺 & 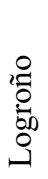 & $\stackrel{80}{=}$ & $\begin{array}{l}\frac{\vec{T}}{\vec{B}} \\
\frac{\pi}{\Sigma}\end{array}$ & 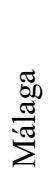 & 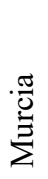 & $\begin{array}{l}\text { T्ञ } \\
\text { J } \\
\text { Z } \\
\text { Z }\end{array}$ & 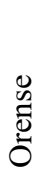 & $\frac{\frac{0}{0}}{\frac{0}{8}}$ & $\frac{\frac{\pi}{0}}{\frac{0}{0}}$ \\
\hline
\end{tabular}

Hispania, 2020, vol. LXXX, n. ${ }^{\circ} 264$, enero-abril, págs. 109-137, ISSN: 0018-2141, e-ISSN: 1988-8368 https://doi.org/10.3989/hispania.2020.004 


\begin{tabular}{|c|c|c|c|c|c|c|c|c|c|c|c|c|c|c|c|c|c|}
\hline \multirow{4}{*}{ 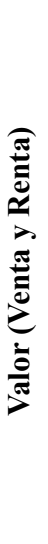 } & $\partial \stackrel{\bar{\sigma}}{\theta}$ & $\stackrel{+}{\sigma}$ & $\tilde{n}^{2}$ & $\stackrel{\circ}{0}$ & $\overrightarrow{0}$ & $\tilde{\sim}$ & $\stackrel{0}{0}$ & & $\stackrel{+}{\circ}$ & $\begin{array}{l}0 \\
6\end{array}$ & & 0 & $\stackrel{+}{0}$ & $\stackrel{+}{0}$ & $\tilde{\sigma}$ & $\stackrel{\theta}{\theta}$ & $\begin{array}{l}\tilde{0} \\
: 0 \\
: 0\end{array}$ \\
\hline & 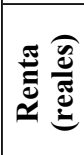 & $\begin{array}{l}0 \\
\stackrel{n}{n} \\
\end{array}$ & 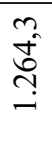 & $\stackrel{\circ}{\infty}$ & $\stackrel{0}{\hat{\sigma}}$ & 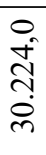 & $\begin{array}{l}0 \\
0 \\
0\end{array}$ & & $\begin{array}{l}\overrightarrow{6} \\
\stackrel{0}{0} \\
\stackrel{n}{-}\end{array}$ & 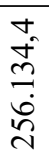 & & $\tilde{\sigma}$ & $\begin{array}{l}\sigma \\
\hat{\sigma} \\
-1\end{array}$ & $\begin{array}{l}0 \\
\stackrel{0}{0} \\
\stackrel{0}{0} \\
\stackrel{-}{-}\end{array}$ & $\begin{array}{c}\sigma^{\infty} \\
\text { } \\
\sigma\end{array}$ & 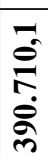 & $\begin{array}{l}\overrightarrow{0} \\
0 \\
0 \\
\pi \\
\pi\end{array}$ \\
\hline & o $\frac{\bar{\sigma}}{\theta}$ & $\stackrel{\circ}{\circ}$ & $\overbrace{}^{2}$ & 0 & $\overrightarrow{0}$ & $\vec{a}$ & $\overrightarrow{0}$ & & $\mathfrak{n}^{2}$ & 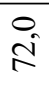 & & 0. & $\tilde{n}^{n}$ & $\hat{m}^{n}$ & $\begin{array}{l}0 \\
0\end{array}$ & $\stackrel{\theta}{\hat{\theta}}$ & à \\
\hline & 跣 & $\begin{array}{l}\stackrel{0}{\circ} \\
\stackrel{\infty}{\sim}\end{array}$ & 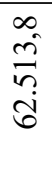 & 每 & $\begin{array}{l}0 \\
\stackrel{0}{\circ} \\
\infty \\
\stackrel{1}{1}\end{array}$ & $\begin{array}{l}\hat{\sigma} \\
\stackrel{0}{0} \\
\stackrel{0}{0} \\
\hat{\sigma}\end{array}$ & 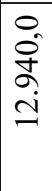 & & $\begin{array}{c}\stackrel{0}{n} \\
\stackrel{\sim}{\sim} \\
\stackrel{n}{n}\end{array}$ & 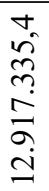 & & $\begin{array}{l}0 \\
0 \\
n \\
n \\
n\end{array}$ & 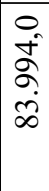 & $\begin{array}{l}\hat{\sigma} \\
\delta \\
\dot{0} \\
i n \\
i n\end{array}$ & 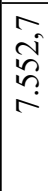 & 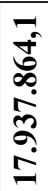 & $\begin{array}{l}\dot{N} \\
\dot{0} \\
\stackrel{0}{0} \\
\infty \\
\infty \\
\infty\end{array}$ \\
\hline 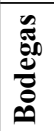 & $\ddot{z}$ & & & & & & & & & & & - & & & & - & 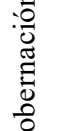 \\
\hline 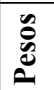 & $\ddot{z}$ & & & & & & & & & & & & & & - & - & \\
\hline 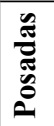 & $\ddot{z}$ & & & & & & & & & - & & & & - & & $m$ & $\begin{array}{l}\overline{0} \\
.0 \\
.\end{array}$ \\
\hline 冚 & $\ddot{Z}$ & & & & & & & & & & & & & & $\sim$ & $m$ & 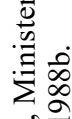 \\
\hline$\frac{\mathscr{E}}{\stackrel{\Xi}{\Xi}}$ & $\ddot{z}$ & & & & & & & & $N$ & - & & & & & - & $=$ & 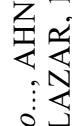 \\
\hline \multirow[t]{2}{*}{ 离 } & $\sum$ & & & & & & & & & & & $\begin{array}{l}a \\
\infty \\
\infty\end{array}$ & & $\hat{n}$ & & 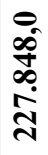 & 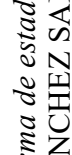 \\
\hline & $\ddot{z}$ & & - & - & & - & & & & $N$ & & $m$ & & $N$ & & 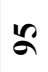 & \\
\hline \multirow[t]{2}{*}{ 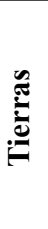 } & 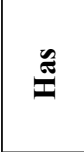 & & $\hat{\sigma}$ & $\underset{r}{\stackrel{\nabla}{r}}$ & $\overrightarrow{0}$ & 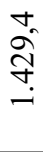 & ก̊ & & $\overrightarrow{0}$ & 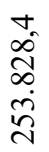 & & $\hat{\sigma}$ & & & & 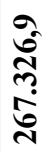 & 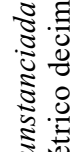 \\
\hline & $\ddot{z}$ & - & - & $\nabla$ & - & $\nabla$ & N & & - & $\overline{0}$ & & $N$ & & & & 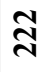 & 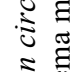 \\
\hline & لَّ & $\begin{array}{l}\frac{\pi}{3} \\
0 \\
0 \\
0 \\
0 \\
0 \\
0\end{array}$ & 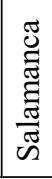 & 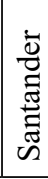 & 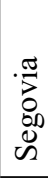 & 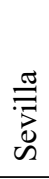 & 苛 & 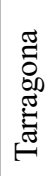 & 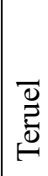 & $\frac{\frac{0}{0}}{\frac{0}{0}}$ & $\frac{\frac{\pi}{0}}{\frac{0}{0}}$ & 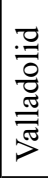 & 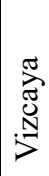 & 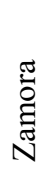 & 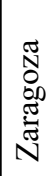 & $\frac{\mathbb{Z}}{\sqrt{2}}$ & 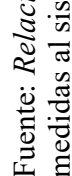 \\
\hline
\end{tabular}

Hispania, 2020, vol. LXXX, n. ${ }^{\circ} 264$, enero-abril, págs. 109-137, ISSN: 0018-2141, e-ISSN: 1988-8368 https://doi.org/10.3989/hispania.2020.004 
No conviene, sin embargo, infravalorar la magnitud de la última desamortización absolutista. Y no solo porque, en clave política, permite hablar de continuidad y no de ruptura con relación a la reforma económica liberal, sino porque, más allá de la valoración monetaria, afectó prácticamente a todas las provincias españolas. Para algunos pueblos, incluso, la enajenación gubernativa de la Década Ominosa llegó a tener mayor envergadura que las ventas en pública subasta de Pascual Madoz. Es el caso de los Montes de Toledo sobre el que más tarde volveremos, pero también el de Betanzos (A Coruña), donde el Ayuntamiento adjudicó a censo perpetuo todos los terrenos eriales de la ciudad (937 ferradas), o el de Trigueros (Huelva), donde la enajenación afectó a toda la superficie de la Dehesa Labradillos (1.782 hectáreas).

Mención especial merece el caso de Sevilla, aunque no tanto por la superficie enajenada en el término de la ciudad, que también (más de 1.400 hectáreas), como por la relevancia que en las últimas décadas ha adquirido la especialización agrícola de esta superficie. Nos referimos a la Isla Mayor del Guadalquivir, una marisma convertida actualmente en la mayor productora de arroz de toda España. Siguiendo la estela de la vecina Isla Menor, enajenada a censo por el Ayuntamiento hispalense en 1816 para hacer frente a las deudas contraídas durante la Guerra de la Independencia y durante la visita a la ciudad de la futura mujer de Fernando VII ${ }^{60}$, parte de esta propiedad, tradicionalmente explotada por grandes ganaderos de Sevilla bajo la excusa de ser tierra de aprovechamiento común, fue reclamada en 1822 por Fernando de la Sierra, empresario gaditano, en virtud del Decreto de 29 de junio de $1822^{61}$. Con él, el gobierno nacido del pronunciamiento de 1820 trató de refundir en uno solo todos los mandatos emanados del liberalismo desde el Decreto de 4 de enero de 1813, intentando, así, reactivar los repartos ordenados en aquel entonces, aunque incorporando, entre los adjudicatarios, a los beneficiarios de propios, arbitrios, baldíos o comunes vendidos durante el conflicto napoleónico. Con el fin de resolver los persistentes problemas del tesoro local, el Decreto de 29 de junio de 1822 dispuso, además, que:

... los terrenos que no pueden entrar en suertes por ser pantanosos, riscos, cordilleras de sierras u otra causa que los haga actualmente infructíferos, se adjudicarán a

${ }^{60}$ La Isla Menor fue enajenada en favor de la Real Compañía de Navegación del Guadalquivir (DEL MORAL ITUARTE, 1989. GONZÁLEZ ARTEAGA, 2008).

${ }^{61}$ Para conocer los entresijos por los que discurrió el proceso privatizador de Isla Mayor, resulta indispensable la obra de RODRÍGUEZ CÁRDENAS, 1994. Conviene precisar, al respecto, que, aunque la documentación que sirve de base a este trabajo no la incluye, la parte más extensa de la isla (cerca de 5.500 hectáreas) fue adjudicada a censo enfitéutico, en 1829, al banquero Felipe Ruiz, marqués de Casa Riera a cambio de un canon anual de 60.000 reales. La cesión de esta parte de la marisma fue ratificada por Real Orden de 8 de marzo de 1830, aunque tuvo que superar posteriormente diversas demandas judiciales hasta ser finalmente inscrita como propiedad privada.

Hispania, 2020, vol. LXXX, n. ${ }^{\circ} 264$, enero-abril, págs. 109-137, ISSN: 0018-2141, e-ISSN: 1988-8368 
los que lo soliciten, siempre que se obliguen a desecar los unos, plantar de árboles los otros o hacerlos de cualquier manera productivos en determinado tiempo ${ }^{62}$.

En base a esta posibilidad y a la ayuda prestada por Fernando de la Sierra para vestir a las tropas sevillanas encargadas de contener la invasión de los Cien Mil Hijos de San Luis, el empresario obtuvo en 1823 del consistorio hispalense la cesión del dominio útil de treinta suertes, de 100 aranzadas cada una, en las tierras de mejor calidad de la Isla Mayor del Guadalquivir, con el compromiso de:

... emplear toda su fortuna en el fomento y cultivo del terreno comprado, teniendo preparadas bombas de vapor para el riego, con la intención de extenderlo lo más posible y formar prados artificiales, hacer plantaciones de todas clases, hermosear las orillas del Guadalquivir con arbolado y, sobre todo, impedir, si fuese posible, las inundaciones ${ }^{63}$.

Pese a los intentos de recuperación posterior por parte del Ayuntamiento de Sevilla y pese al explícito apoyo prestado por Fernando de la Sierra a la causa liberal, el empresario obtuvo de Fernando VII la confirmación regia de la enajenación por Real Orden de 21 de mayo de 1825. Ignoramos qué pasó exactamente a partir de entonces. Nos consta que el empresario gaditano comenzó a realizar las obras de mejora prometidas, aunque nunca llegó a terminarlas. Sabemos, también, que fue su sobrino, Joaquín de la Concha y Sierra, fundador de una de las grandes sagas de ganadería brava existentes en España ${ }^{64}$, el que arrendó primero y heredó después la finca adquirida en Isla Mayor. Desconocemos, no obstante, en qué momento tuvo lugar la refundición de dominios, si es que realmente la hubo. Por las facilidades que concedió a los censatarios la Ley de 1 de mayo de $1855^{65}$ y por las noticias disponibles para otras transferencias realizadas en Isla Mayor ${ }^{66}$, sospechamos que fue entonces cuando se redimió el censo impuesto sobre la citada heredad, pero no podemos asegurarlo.

La misma incertidumbre rodea a otra de las grandes transferencias recogidas en la Relación circunstanciada... de 1833: la adjudicación a censo de 6.020 aranzadas en Jerez de la Frontera (Cádiz) por Real Orden de 19 de septiembre 1828. Según ha estudiado J.I. Jiménez Blanco, esta cesión o «merced» afectó a tierras baldías y recayó en Pedro Pérez Muñoz, un empresario malagueño con

${ }^{62}$ Colección de los Decretos y las Órdenes..., 1822, vol. IX: 562-569.

${ }^{63}$ GONZÁLEZ ARTEAGA, 2008: 17.

${ }^{64}$ Véase MIRA, 1979.

${ }^{65}$ JIMÉNEZ BLANCO y LINARES, 74 (Murcia, 2018): 52-54.

${ }^{66}$ El censo perpetuo impuesto sobre las marismas enajenadas al marqués de Casa Riera en 1829 (véase nota 60) fue redimido por el propio marqués en 1856 (RODRÍGUEZ CÁRDENAS, 2010: 42). 
negocios en América del que poco más sabemos. Las fincas fueron adjudicadas con la prohibición expresa de ser transmitidas a manos muertas y con la obligación de pagar una renta anual del $4 \%$ sobre el valor de lo producido por el cultivo o por el arrendamiento de las tierras, pero no a la hacienda municipal, sino a la Hacienda Real, una prueba más «de que, en la práctica, los monarcas españoles dispusieron siempre de los baldíos como si fueran tierras de realengo» ${ }^{67}$. La cuestión es que, más allá de las quejas a las que dio lugar durante los años treinta y cuarenta del siglo XIX por contener varias suertes repartidas previamente con arreglo al Decreto de 29 de junio de 1822, la cesión realizada a favor de Pedro Pérez Muñoz tampoco parece haber sido objeto de redención alguna ni antes ni después de 1855 . De hecho, la información de la que dispone J.I. Jiménez Blanco apunta a que, tras la confusión generada a raíz de la devolución de las tierras repartidas durante el Trienio Liberal y una vez activada la Ley de Desamortización General de 1855, la adjudicación fue olvidada por la superioridad jerezana, quedando implícitamente consolidada la plena propiedad de la tierra adjudicada ${ }^{68}$.

Mucho más combativa sería la actitud de algunos ayuntamientos ante la enajenación de los Montes de Toledo por Real Orden de 27 de agosto 1827. Con ella, Fernando VII daba por finiquitada la mancomunidad de pastos que habían disfrutado hasta entonces los 16 pueblos ubicados en los montes propios de la ciudad y ordenaba señalar a cada pueblo «un término de tierra correspondiente a su población», con el fin de distribuirlo «entre los vecinos para que lo descuajasen y cultivasen». La medida encargaba a los concejos implicados repartir entre los vecinos las tierras que quedaran «después de separadas las necesarias para dehesa boyal, obrándose en ello con sujeción a la Real Provisión de 26 de mayo de 1770». De esta manera, como bien afirma A. Gallego Anabitarte, «la relación jurídica que se establecía entre los vecinos adjudicatarios de los repartimientos y su dueño, en este caso la ciudad de Toledo, era en esta época un arrendamiento» ${ }^{69}$. En esencia, pues, a pesar de la fórmula de adjudicación a la que hacía referencia la Relación circunstanciada..., de 1833 (cesión perpetua), la Real Orden de 27 de agosto de 1827 dejaba completamente intacta la propiedad municipal ${ }^{70}$.

Sería realmente a partir de la definitiva consolidación del régimen liberal en España, tras la muerte de Fernando VII, cuando la adjudicación de los Montes de Toledo comenzaría a adoptar la forma de una verdadera desamortización. Y es que, junto a las fincas repartidas durante la Guerra de la Independencia, las concedidas por Decreto de 4 de enero de 1813 «en las dos épocas que ha regido» y

67 JIMÉNEZ BLANCO, 1996: 108.

${ }^{68}$ Véase también CABRAL, 1995: 233-234.

69 GALLEGO ANABITARTE, 1993a: 80-81.

70 Sobre la confusión que ha generado en la historiografía española la Real Provisión de 26 de mayo de 1770, véase JIMÉNEZ BLANCO y LINARES, 74 (Murcia, 2018): 43. 
todas las adjudicadas «con orden superior competente», la Real Orden de 18 de mayo de 1837 reconocía la posesión de las suertes repartidas por Real Provisión de 1770 a los que hubieran seguido pagando el canon inicialmente establecido a los ayuntamientos correspondientes como si de un contrato enfitéutico se tra$\operatorname{tara}^{71}$. El censo perpetuo, sin embargo, no garantizaba la plena propiedad de los adjudicatarios originarios: en una supuesta redención, como la prevista en la Ley de 1 de mayo de 1855, el dominio útil podía recaer en alguien distinto a quien lo ostentara en el momento mismo de la redención. Esto era lo que intentaba evitar la Ley de Desamortización General al otorgar a los censatarios un benévolo plazo de seis meses para redimir censos. La legislación posterior, más concretamente la Ley de 6 de mayo de 1855, ampliaba los plazos para la redención, pero, además, reconocía explícitamente la propiedad particular de «las suertes que, de terrenos baldíos, realengos, comunes, propios y arbitrios, se repartieron con las formalidades prescritas en la Real Provisión de 26 de mayo de $1770 \gg^{72}$.

Es en esta tesitura en la que habría que situar el conflicto abierto por algunos concejos toledanos contra los traspasos ordenados por Fernando VII. El principal contencioso, iniciado por el Ayuntamiento de Los Yébenes en 1988 y alimentado por los informes emitidos por el reputado jurista A. Nieto ${ }^{73}$, partía de la base de que los predios adjudicados por el último monarca absoluto habían dejado de ser «propios» de Toledo y habían pasado a ser «terrenos de aprovechamiento común» para los vecinos de cada uno de los pueblos ubicados en los montes de la ciudad. Justificaba esta apreciación el hecho de que, en la constitución del censo impuesto en 1848 sobre los predios adjudicados a Los Yébenes, constaba como enfiteuta el conjunto de los vecinos del lugar y no cada vecino en particular, aunque, según A. Gallego Anabitarte, por la imposibilidad de serlo individualmente dada la infertilidad de dichos terrenos. Es más, en las escrituras de redención del censo de 1856 aparecían como otorgantes «los referidos vecinos de Yébenes» o los que actuaban en nombre de ellos, pero no el Ayuntamiento ni el común de los vecinos. En realidad, hasta 1876 no resultarían repartidas entre los condueños originarios (1.045 en total) los predios concedidos en $1827^{74}$. Estaríamos hablando, en definitiva, de una disputa judicial que, más que la privatización en sí misma, parecía discutir la naturaleza jurídica de la propiedad privatizada una vez desamortizada ${ }^{75}$.

71 Colección de las Leyes..., 1837, vol. XII: 244-245.

72 Colección de las Leyes..., 1856, vol. LXV: 45-46.

${ }^{73}$ Recogidos en NIETO, 1997.

74 GALLEGO ANABITARTE, 1993b: 73-110; 1998: 43-44.

75 En julio de 2006, el Tribunal Supremo desestimaba el último recurso interpuesto por el Ayuntamiento de Los Yébenes contra las sentencias emitidas anteriormente en favor de los herederos de los terrenos repartidos en 1827. Disponible en http://www.europapress.es/castilla-lamancha/noticia-ts-desestima-recurso-ayuntamiento-yebenes-tole-do-contra-vecinos-titularidad-varias-fincas-20060707175952.html (consultado el 20 de abril de 2018). 
Fuera como fuese, la verdad es que las escasas monografías realizadas hasta la fecha, ninguna de ellas conectadas entre sí, impiden rastrear la senda recorrida por las fincas enajenadas durante la Década Ominosa. Parece probable que la titularidad de muchas de ellas acabara siendo consolidada a través de las distintas vías - y prórrogas - de redención que abrió en 1855 la Ley de Desamortización General. También es posible que algunas, como las cedidas en Jerez de la Frontera, resultaran finalmente reconocidas como propiedad privada por la simple aceptación de los hechos consumados. Es casi seguro que otras tantas, al igual que las adjudicadas en Toledo, serían sometidas a complejas demandas de las que difícilmente habrían salido favorecidas las entidades demandantes. De lo que no cabe duda es de que la elaboración de una lista oficial de fincas enajenadas durante la última monarquía absoluta indicaba con claridad que, sin estar aún preparada para asumir una cesión integral como la que proponía la Dirección General de Propios y Arbitrios del Reino, la Corona española estaba visiblemente comprometida con alguna que otra forma de privatizar la antigua riqueza concejil y comunal.

Desde esta perspectiva y con las cifras en la mano sería absolutamente incongruente seguir hablando de inercia o ruptura a la hora de describir la dinámica de la desamortización municipal durante la doble reacción absolutista. Por tímida y arbitraria que fuera, la enajenación a la carta ideada desde la Contaduría General de Propios y Arbitrios del Reino derribaba el débil muro que el propio absolutismo había levantado y mantenido durante siglos sobre el patrimonio local: aquél que separaba a los bienes de propios, arbitrios y comunes de los baldíos y realengos ${ }^{76}$. Cómo interpretar, si no, el traspaso de los Montes de Toledo, unos terrenos poseídos y gestionados como propios por el Ayuntamiento de la ciudad desde $1246^{77}$. Tal y como parecían demostrar los primeros pasos del reinado de Fernando VII, el país había cambiado al calor del conflicto napoleónico y el último monarca absoluto no estaba dispuesto a desperdiciar los réditos del cambio. De hecho, como finalmente haría, podía aprovecharlo para romper los compromisos tiempo atrás adquiridos con el poder local y utilizar en beneficio propio el patrimonio concejil y comunal.

\section{CONCLUSIONES}

Después de años de investigación, nadie duda actualmente de que la Ley de 1 de mayo de 1855 o Ley de Pascual Madoz supuso para España el pistoletazo

${ }^{76}$ «Para los pueblos todo esto eran sutilezas intrascendentes: el patrimonio municipal, dentro de su variedad, era único, como habían entendido los clásicos y como venía entendiéndose por tradición: lo que hoy se aprovechaba comunal y gratuitamente, mañana se arrendaba a extraños o a los mismos vecinos (mediante un arbitrio) según fuera la situación de la caja municipal», NIETO, 1964: 130.

77 Véase, al respecto, LORENTE, 12 (Madrid, 1990): 73.

Hispania, 2020, vol. LXXX, n. ${ }^{\circ} 264$, enero-abril, págs. 109-137, ISSN: 0018-2141, e-ISSN: 1988-8368 
de salida de un proceso de privatización sin precedentes en la historia de la propiedad municipal. Gracias, además, a la propia revisión historiográfica de este proceso, la denominada «desamortización antes de la desamortización», es decir, la privatización de una parte importante de la antigua riqueza concejil y comunal durante las décadas previas a la Ley de Desamortización General de 1855, parece haber calado finalmente en la interpretación más extendida de la reforma económica liberal. Dentro de tal interpretación, sin embargo, la doble reacción absolutista (1814-1820 y 1823-1833) ha quedado implícita o explícitamente definida como una etapa de parálisis total en la política de privatización municipal desarrollada por las Cortes de Cádiz. La presente investigación intenta matizar $\mathrm{y}$, por qué no, desacreditar esta errónea consideración, aportando potentes pruebas que proceden, por una parte, de la bibliografía especializada y, por otra, de la documentación primaria conservada en el Archivo Histórico Nacional.

De la literatura al uso, la conclusión más relevante es quizá aquella que, superando la falsa contraposición entre monarquía absoluta y desamortización municipal, insiste en la idea de que la Corona fue durante el Antiguo Régimen una de las primeras interesadas en la privatización de la antigua riqueza concejil y comunal. Es verdad que, casi siempre, la acción directa de la monarquía, normalmente vinculada a la deuda de la hacienda central, afectó a baldíos y realengos, pero también es cierto que la inacción del absolutismo en materia de financiación local contribuyó indirectamente a privatizar el uso de la propiedad comunal, cuando no a enajenar, sin más, parte de la riqueza apropiada o arbitrada para sufragar los gastos de la administración municipal.

Por otra parte, la bibliografía especializada ha puesto recientemente el foco en la importancia de la vecindad como protagonista de la amputación territorial. Desde esta perspectiva, la política o, mejor dicho, la legislación sobre privatización deja de ser una variable independiente y sobrevenida, ajena a la colectividad, para pasar a ser una compleja construcción social que nace, evoluciona y, a veces, cambia a la sombra de la dinámica de la sociedad. Si es así, la última monarquía absoluta no puede ser concebida de ninguna manera como una fase de interrupción en la reforma económica liberal, no solo porque, tal y como evidencian algunas monografías recientes, resultaron ser las ventas espontáneas de la Guerra de la Independencia las que realmente dictaron la agenda política de las Cortes de Cádiz en materia de desamortización municipal, sino porque fue, precisamente, la legislación emanada de la reacción absolutista la que convirtió, por primera vez, la roturación arbitraria en una vía más de privatización de la riqueza concejil y comunal.

La documentación que conserva el Archivo Histórico Nacional de la Dirección General de Propios y Arbitrios del Reino confirma la irreversibilidad de algunos de los cambios producidos en la sociedad española tras la invasión napoleónica e, incluso, revela la existencia de una corriente tecnocrática, abiertamente 
partidaria de la desamortización municipal, en las entrañas mismas de la administración absolutista. Es verdad que las propuestas de privatización integral emanadas de esta corriente, liderada por Niceto Larreta y secundada por diversas intendencias de provincia, no llegaron nunca a cuajar en la legislación fernandina. No obstante, la vinculación establecida en estas propuestas entre, por una parte, la enajenación de la riqueza local y, por otra, la reducción de la deuda municipal, la liberalización del mercado laboral, la «perfección» de la propiedad e, incluso, la adhesión de partidarios a la causa absolutista traza una delgada pero sólida línea de continuidad que entronca claramente con algunas de las claves de la reforma económica liberal.

En definitiva, además, la riquísima información cuantitativa que aporta la Dirección General de Propios y Arbitrios del Reino para la etapa comprendida entre 1824 y 1832, presentada por primera vez en esta investigación, demuestra que, aun cuando la fórmula finalmente elegida por la última monarquía absoluta - la enajenación gubernativa - arrojó cifras exiguas en comparación con las que, según esta misma institución, sumaron las ventas de la Guerra de la Independencia, la privatización de la riqueza local siguió estando a la orden del día durante la Década Ominosa. Es más, la presencia de fincas apropiadas o arbitradas entre las concedidas por la Corona a manos privadas y la participación de casi todas las provincias españolas en las transferencias producidas tras la segunda reacción absolutista invitan a rechazar, de una vez por todas, cualquier suspicacia acerca de la estrecha conexión existente entre monarquía y desamortización municipal. En suma, gracias a la documentación primaria que ofrece en exclusiva la presente investigación, será difícil, a partir de ahora, seguir hablando de interrupción o de inmovilidad al hacer referencia a la política de privatización mantenida por la Corona durante la última restauración absolutista.

\section{Bibliografía}

Alonso, M. ${ }^{a}$ Paz, «Ventas de bienes municipales en la provincia de Salamanca durante la Guerra de la Independencia», en Desamortización y Hacienda Pública, Madrid, Ministerio de Agricultura y Ministerio de Economía y Hacienda, 1986, vol. I: 369-384.

Artiaga, Aurora, A desamortización na provincia de Pontevedra (1855-1900), Pontevedra, Diputación Provincial de Pontevedra, 1991.

Bravo, Juan J. y Fernández Paradas, Mercedes, «La venta de baldíos en la Andalucía del quinientos: las reformaciones de Junco de Posada», Chronica nova: Revista de historia moderna de la Universidad de Granada, 28 (Granada, 2001): 83-103.

Cabral, Antonio, Propiedad comunal y repartos de tierras en Cádiz (siglos XV-XIX), Sanlúcar de Barrameda, Consejo Regulador de las Denominaciones de Origen Jerez-Xéréz-Sherry y Manzanilla, 1995.

Calvo, José, «Venta de baldíos y tensión social en Andalucía a mediados del siglo XVII», Agricultura y Sociedad, 55 (Madrid, 1990): 95-123. 
Castrillejo, Félix M. , La desamortización de Madoz en la provincia de Burgos (18551869), Valladolid, Universidad de Valladolid, 1987.

Colección de las Leyes, Decretos y Declaraciones de las Cortes y de los Reales Decretos, Órdenes, Resoluciones y Reglamentos Generales, Madrid, Imprenta Nacional, 1837 y 1856 , vols. XII y LXV.

Colección de los Decretos y las Órdenes que han expedido las Cortes Generales y Extraordinarias, Madrid, Imprenta Nacional, 1822, vol. IX.

Congost, Rosa, «Sagrada propiedad imperfecta. Otra visión de la revolución liberal española», Historia Agraria, 20 (Murcia, 2000): 61-93.

Coronas, Luis J., «Una comisión para la venta de baldíos en el Reino de Jaén a mediados del siglo XVII», Andalucía Moderna: actas del II Congreso de Historia de Andalucía: Córdoba, 1991, Córdoba, Junta de Andalucía y Cajasur, 1994: 79-86.

De la Torre, Joseba, Los campesinos navarros ante la guerra napoleónica. Financiación bélica y desamortización civil, Madrid, Ministerio de Agricultura, 1991.

Decretos de Nuestra Señora Doña Isabel II por su Augusta Madre la Reina Gobernadora, Madrid, Imprenta Real, 1824, vol. VII.

Decretos del Rey Don Fernando VII, Madrid, Imprenta Real, 1818-1820 y 1823-1830, vols. I-XIV.

Del Moral Ituarte, Leandro, «Un intento frustrado de acondicionamiento del Guadalquivir: la actuación de la Real Compañía de navegación en la primera mitad del siglo XIX: nuevas aportaciones y replanteamiento geo-histórico de un tema polémico», Mélanges de la Casa de Velázquez, 25 (Madrid, 1989): 327-353.

Del Valle, Ángel R., El poder de la propiedad: Élites y desamortización en la España interior (Madrid y Castilla-La Mancha), Toledo, Almud, 2015.

Del Valle, Ángel R., «Estrategias y actitudes del poder local ante la privatización de las tierras concejiles en la España interior (Ciudad Real, 1855-1910)», Historia Agraria, 69 (Murcia, 2016): 105-135.

Diario de Sesiones de las Cortes Generales y Extraordinarias, legislatura 1810-1813, Madrid, Imprenta Nacional, 1813.

Díez Espinosa, José R., «La desamortización de censos», Ayer, 9 (Madrid, 1993): 61-104.

Domínguez Ortiz, Antonio, «La comisión de D. Luis Gudiel para la venta de baldíos en Andalucía», Congreso de historia rural: siglos XV-XIX: actas del coloquio celebrado en Madrid, Segovia y Toledo del 13 al 16 de octubre de 1981, Madrid, Casa de Velázquez, 1984: 511-522.

Fernández Arroyo, Margarita, «Los aprovechamientos concurrentes sobre una misma finca rústica en Extremadura: una manifestación de la supervivencia actual del denominado en la Edad Media dominio dividido», Anuario de la Facultad de Derecho, 11 (Cáceres, 1993): 523-544.

Fernández Carrión, Rodrigo, «Funcionalidad económica de los baldíos. El problema de su venta en la Andalucía del siglo XVII», Revista de Historia Económica, 2/3 (Madrid, 1984): 163-182.

Fernández de Pinedo, Emiliano, «La entrada de la tierra en el circuito comercial: la desamortización en Vascongadas. Planteamientos y primeros resultados», en Jordi Nadal y Gabriel Tortella (eds.), Agricultura, comercio colonial y crecimiento económico en la España contemporánea, Barcelona, Ariel, 1974: 100-128. 
Fernández Paradas, Mercedes, Los repartos de tierras municipales en Málaga, 17671842, Málaga, Universidad de Málaga, 2002.

Fernández Paradas, Mercedes, «Los repartos de tierras municipales en Andalucía (1767-1854): Nuevas evidencias», Historia Agraria, 34 (Murcia, 2004a): 39-60.

Fernández Paradas, Mercedes, Propios, Arbitrios y Comunales. El patrimonio territorial del Concejo de Antequera (siglos XV-XIX), Málaga, Diputación de Málaga, 2004b.

Fernández Paradas, Mercedes, «Apropiación y privatización de tierras municipales en Andalucía: Tres ejemplos malagueños (1750-1855)», Tiempos Modernos: Revista Electrónica de Historia Moderna, 7/21 (Logroño, 2010): 1-27.

Fontana, Josep, «La financiación de la Guerra de la Independencia», Hacienda Pública Española, 69 (Madrid, 1981): 209-217.

Fontana, Josep, La crisis del Antiguo régimen, 1808-1833, Barcelona, Crítica, 1983 [1979].

Fontana, Josep, «La desamortización de Mendizábal y sus antecedentes», en Ángel García Sanz y Ramón Garrabou (eds.), Historia agraria de la España contemporánea. 1. Cambio social y nuevas formas de propiedad (1800-1850), Barcelona, Crítica, 1985: 219-244.

Fontana, Josep, La quiebra de la monarquía absoluta, 1814-1829, Barcelona, Ariel, 1987.

Fontana, Josep y Garrabou, Ramón, Guerra y Hacienda. La Hacienda del gobierno central en los años de la Guerra de la Independencia (1808-1814), Alicante, Instituto Juan Gil-Albert/Diputación Provincial de Alicante, 1986.

Fuentes, Senador, La desamortización antes de la desamortización. Los bienes concejiles en la Baja Extremadura (1793-1855), tesis doctoral, UNED Madrid, 1993.

Gallego Anabitarte, Alfredo, La desamortización de los montes de Toledo, Madrid, Marcial Pons, 1993a.

Gallego Anabitarte, Alfredo, Jurisdicción, propiedad y desamortización (redención de censos y ventas) en los Montes de Toledo (Documentación, 1820-1950), Madrid, Marcial Pons, 1993b.

Gallego Anabitarte, Alfredo, Reparto y venta de tierras concejiles. Ilusión y Derecho (Los Montes de Toledo), Madrid, Montecorvo, 1998.

García García, Carmen, La crisis de las haciendas locales: de la reforma administrativa a la reforma fiscal (1743-1845), tesis doctoral, Universidad Autónoma de Madrid, 1994.

García González, Miguel J., La desamortización de Madoz en El Bierzo, Ponferrada, Institución Virgen de la Encina, 1996.

García Pérez, Juan, «Efectos de la desamortización sobre la propiedad y los cultivos», Ayer, 9 (Madrid, 1993): 105-173.

García Pérez, Juan y Sánchez Marroyo, Fernando, «Extremadura a fines del siglo XVIII y comienzos del XIX: conflictos campesinos, crisis agrarias y crisis de subsistencias y agobios fiscales», Norba, 5 (Cáceres, 1984): 213-233.

García Rodríguez, Alfonso, Propiedad y territorio: La desamortización del siglo XIX en Requena (1768-1900), Requena, Ayuntamiento de Requena, 2015.

García Sanz, Ángel, «Bienes y derechos comunales y el proceso de su privatización en Castilla durante los siglos XVI y XVII. El caso de las tierras de Segovia», Hispania, 144 (Madrid, 1980): 95-127. 
Gómez Álvarez, J. Ubaldo, «El censo redimible y al quitar: un mecanismo real de transferencia de la propiedad», Estudis: Revista de Historia Moderna, 6 (Valencia, 1977): 5-26.

Gómez Mendoza, Josefina, «La venta de baldíos y comunales en el siglo XVI. Estudio de su proceso en Guadalajara», Estudios Geográficos, 28/109 (Madrid, 1967): 499-559.

Gómez Urdáñez, Gracia, «Doctrinas y realidades: Los frenos a la liberalización de la propiedad en España, 1835-1855», Historia Agraria, 27 (Murcia, 2002): 133-163.

González Arteaga, José, Las Marismas del Guadalquivir: etapas de su aprovechamiento económico, Sevilla, C.P. Antonio Cuevas, 1993.

González Arteaga, José, El rincón de los Lirios. Las islas del Guadalquivir 1927-1930, Sevilla, Centro de Estudios Andaluces, 2008.

González Marzo, Félix, La desamortización de Madoz en la provincia de Cuenca (1855-1866), Cuenca, Diputación Provincial de Cuenca, 1993.

González Marzo, Félix, La desamortización de Madoz en la provincia de Guadalajara (1855-1896): Algunas claves para el conocimiento de la sociedad provincial contemporánea, Guadalajara, Caja de Ahorros de Guadalajara, 2008.

Herr, Richard, «Hacia el derrumbe del Antiguo Régimen: crisis fiscal y desamortización bajo Carlos IV», Moneda y Crédito, 118 (Madrid, 1971): 37-100.

Infante, Javier, «La desamortización de las casas de propios a finales del siglo XVIII en la ciudad de Salamanca», en Desamortización y Hacienda Pública, Madrid, Ministerio de Agricultura/Ministerio de Economía y Hacienda, 1986, vol. I: 317-337.

Iriarte-Goñi, Iñaki, Bienes comunales y capitalismo agrario en Navarra, Madrid, Ministerio de Agricultura, 1996.

Jiménez Blanco, J. Ignacio, Privatización y apropiación de tierras municipales en la Baja Andalucía. Jerez de la Frontera, 1750-1995, Jerez de la Frontera, Ayuntamiento de Jerez, 1996.

Jiménez Blanco, J. Ignacio y Linares, Antonio M., «La cara oculta de la desamortización municipal española (1766-1856)», Historia Agraria, 74 (Murcia, 2018): 37-66.

Lana, José M., «La desamortización foral (1841-1861)», Iura Vasconiae, 1 (San Sebastián, 2004): 437-452.

Lana, José M. y De la Torre, Joseba, «Desamortización antes de la Desamortización: Una revisión del proceso desde una perspectiva regional: Navarra, 1808-1859», VII Congreso de la Asociación Española de Historia Económica, Zaragoza, Universidad de Zaragoza, 2001.

Linares, Antonio M., «De la apropiación del usufructo a la privatización de la superficie. Las tierras concejiles en la Baja Extremadura (1750-1850)», Historia Agraria, 9 (Murcia, 1995): 87-127.

Linares, Antonio M., El proceso de privatización de los patrimonios de titularidad pública en Extremadura (1750-1936), tesis doctoral, Universitat de Barcelona, 2002.

Linares, Antonio M., «Los bienes de los pueblos: Del reparto al rescate», en Salustiano de Dios, Javier Infante, Ricardo Robledo y Eugenia Torijano (coords.), Historia de la propiedad: La expropiación, Salamanca, Universidad de Salamanca/ Colegio de Registradores de la Propiedad, 2012: 317-370.

Linares, Antonio M., «La construcción social de la desamortización municipal», en Salvador Calatayud, Jesús Millán y M. ${ }^{a}$ Cruz Romeo (eds.), El Estado desde la 
sociedad: Espacios de poder en la España del siglo XIX, San Vicente del Raspeig, Universitat d'Alacant, 2016: 259-297.

López Estudillo, Antonio, «Los montes públicos y las diversas vías de su privatización en el siglo XIX», Agricultura y Sociedad, 65 (Madrid, 1992): 65-99.

López-Salazar, Jerónimo y Gutiérrez Nieto, Juan I., Estructuras agrarias y sociedad rural en La Mancha (ss. XVI-XVII), Ciudad Real, Instituto de Estudios Manchegos, 1986.

Lorente, Luis, «La desamortización civil en Toledo de 30 de septiembre de 1851», Cuadernos de Historia Contemporánea, 12 (Madrid, 1990): 67-85.

Mangas Navas, José M., El régimen comunal agrario de los concejos de Castilla, Madrid, Ministerio de Agricultura, 1981.

Marcos Martín, Alberto, «Evolución de la propiedad pública municipal en Castilla la Vieja durante la época moderna», Studia Historica: Historia Moderna, 16 (Salamanca, 1997): 57-100.

Marcos Martín, Alberto, «La venta de baldíos en la Castilla del siglo XVI. Viejos problemas, nuevos planteamientos», en Ricardo Franch Benavent y Rafael Benítez Sánchez-Blanco, Estudios de historia moderna: en homenaje a la profesora Emilia Salvador, Valencia, Universitat de València, 2008, vol. 2: 697-728.

Mira, Filiberto, El toro bravo. Hierros y encastes. Prólogo de Vicente Zabala, Sevilla, Caja San Fernando, 1979.

Nieto, Alejandro, Bienes comunales, Madrid, Revista de Derecho Privado, 1964.

Nieto, Alejandro, Bienes comunales de los Montes de Toledo II: reforma agraria vecinal y reforma capitalista, Madrid, Civitas, 1997.

Otaegui, Arantxa, Guerra y crisis de la hacienda local. Las ventas de bienes comunales y de propios en Guipúzcoa, 1764-1814, San Sebastián, Diputación Foral de Guipúzcoa, 1991.

Pereira, José L. y Melón, Miguel Á., «Legislación agraria, colonización del territorio y nuevas poblaciones en Extremadura», en Estructuras agrarias y reformismo ilustrado en la España del siglo XVIII, Madrid, Ministerio de Agricultura, 1989: 785-815.

Pérez Marín, Tomás, «Repartimiento de baldíos y terrenos montuosos: un medio fallido de resolver el problema agrario extremeño en la segunda mitad del siglo XVIII», Studia Historica. Historia Moderna, 17 (Salamanca, 1997): 261-284.

Rodríguez Cárdenas, Matías, Historia de la Isla Mayor del Río Guadalquivir: desde su formación hasta nuestros días, Coria del Río, C. P. Florentina Bou, 1994.

Rodríguez Cárdenas, Matías, Páginas arrancadas en el municipio sevillano de Isla Mayor. Miserias, esperanzas y olvido. Marismas de la margen derecha del Guadalquivir (1923-1945), Sevilla, Ayuntamiento de Isla Mayor/Junta de Andalucía, 2010.

Rodríguez Silva, Antonio, «Venta de baldíos en el siglo XVIII. Una aproximación a su estudio. La Comisión de Baldíos de las Cuatro Villas de la Costa del Mar de Cantabria», en Desamortización y Hacienda Pública, Madrid, Ministerio de Agricultura y Ministerio de Economía y Hacienda, 1986, vol. I: 137-153.

Rueda, Germán, «Bibliografía sobre el proceso desamortizador en España (tercera versión)», Cuadernos de Investigación Histórica, 9 (Madrid, 1986): 191-220.

Rueda, Germán, La desamortización en España: Un balance (1766-1924), Madrid, Arco Libros, 1997.

Hispania, 2020, vol. LXXX, n.o 264, enero-abril, págs. 109-137, ISSN: 0018-2141, e-ISSN: 1988-8368

https://doi.org/10.3989/hispania.2020.004 
Sáez Pombo, Ester y Manuel, Carlos, «La propiedad pública en España (1950-1988). Recopilación bibliográfica», Agricultura y Sociedad, 55 (Madrid, 1990): 315-383.

Sánchez Salazar, Felipa, «Un precedente de la desamortización civil: la facultad concedida en 1801 a los pueblos comprendidos en el ámbito de la Sociedad Cantábrica para repartir los terrenos baldíos», en Desamortización y Hacienda Pública, Madrid, Ministerio de Agricultura/Ministerio de Economía y Hacienda, 1986, vol. I: $155-168$.

Sánchez Salazar, Felipa, Extensión de cultivos en España en el siglo XVIII, Madrid, Siglo XXI, 1988a.

Sánchez Salazar, Felipa, «Medidas de superficie tradicionales y sus equivalencias con el sistema métrico decimal», Agricultura y Sociedad, 49 (Madrid, 1988b): 467-481.

Sánchez Salazar, Felipa, «Incidencia de la ocupación francesa en el medio rural: venta de tierras de propios y comunales. Una aproximación al estado de la cuestión», Agricultura y Sociedad, 55 (Madrid, 1990): 125-166.

Tomás y Valiente, Francisco, El marco político de la desamortización en España, Barcelona, Ariel, 1971.

Vassberg, David E., «La venta de tierras baldías en Castilla durante el siglo XVI», Estudios geográficos, 37/142 (Madrid, 1976): 21-48.

Vassberg, David E., La venta de tierras baldías. El comunitarismo agrario y la corona de Castilla durante el siglo XVI, Madrid, Ministerio de Agricultura, 1983.

Zulueta, José A., «La venta de bienes comunales y concejiles en la tierra de Cáceres», Estudios Geográficos, 36/140-141 (Madrid, 1975): 1.157-1.185.

Recibido: $19 / 06 / 2018$

Aceptado: 26/09/2019 